\title{
Apoptosis, autophagy and unfolded protein response pathways in Arbovirus replication and pathogenesis
}

\author{
MAHMOUD IRANPOUR ${ }^{1} \dagger$, ADEL REZAEI MOGHADAM ${ }^{2} \dagger$, MINA YAZDI $^{3}$, \\ SUDHARSANA R. ANDE ${ }^{4}$, JAVAD ALIZADEH $^{5}$, EMILIA WIECHEC $^{6}$, ROBBIN LINDSAY $^{1}$, \\ MICHAEL DREBOT $^{1}$, KEVIN M. COOMBS $^{7,8}$, SAEID GHAVAMI ${ }^{5,8 *}$ \\ ${ }^{1}$ Zoonotic Diseases and Special Pathogens, National Microbiology Laboratory, Public Health Agency of Canada, \\ 1015 Arlington St., Winnipeg, Manitoba, Canada, ${ }^{2}$ Young Researchers and Elite Club, Ardabil Branch, Islamic \\ Azad University, Ardabil, Iran, ${ }^{3}$ Faculty of Veterinary Medicine, University of Tehran, Tehran, Iran, ${ }^{4}$ Department \\ of Internal Medicine, College of Medicine, Faculty of Health Sciences, University of Manitoba, Winnipeg, Canada, \\ ${ }_{5}^{5}$ Department of Human Anatomy and Cell Science, College of Medicine, Faculty of Health Sciences, University of \\ Manitoba, Winnipeg, Canada, ${ }^{6}$ Department of Clinical and Experimental Medicine (IKE), Division of \\ Otorhinolaryngology, Linkoping University, Linkoping, Sweden, ${ }^{7}$ Department of Medical Microbiology and \\ Infectious Diseases, College of Medicine, Faculty of Health Sciences, University of Manitoba, Winnipeg, Manitoba, \\ Canada, and ${ }^{8}$ The Children Hospital Research Institute of Manitoba, Winnipeg, Canada
}

\begin{abstract}
Arboviruses are pathogens that widely affect the health of people in different communities around the world. Recently, a few successful approaches toward production of effective vaccines against some of these pathogens have been developed, but treatment and prevention of the resulting diseases remain a major health and research concern. The arbovirus infection and replication processes are complex, and many factors are involved in their regulation. Apoptosis, autophagy and the unfolded protein response (UPR) are three mechanisms that are involved in pathogenesis of many viruses. In this review, we focus on the importance of these pathways in the arbovirus replication and infection processes. We provide a brief introduction on how apoptosis, autophagy and the UPR are initiated and regulated, and then discuss the involvement of these pathways in regulation of arbovirus pathogenesis.
\end{abstract}

\section{Introduction}

Arthropod-borne viruses (commonly called arboviruses) typically circulate in nature through biological transmission among susceptible vertebrate hosts and blood-feeding arthropods such as mosquitoes (Culicidae), sand flies (Psychodidae), biting midges (Ceratopogonidae), black flies (Simuliidae) and ticks (Ixodidae and Argasidae) (Refs 1,2). Most of the arboviruses that cause human diseases have RNA genomes and are within the families Flaviviridae, Togaviridae, Bunyaviridae, Reoviridae and Rhabdoviridae which, with few exceptions, are zoonoses that depend on wildlife or domestic animals for maintenance in nature (Ref. 1). Most of the arboviruses that cause disease in humans include: Alphaviruses (Togaviridae: Alphavirus), flaviviruses (Flaviviridae: Flavivirus), bunyaviruses (Bunyaviridae) and some viruses in the families Reoviridae and Rhabdoviridae (Refs 3, 4, 5, 6).

There are currently 534 viruses listed in the International Catalogue of Arboviruses, of which 214 are known to be, or are probably associated with arthropods, 287 viruses are reported to be possible arboviruses and 33 are considered to probably not be, or definitely not be, arboviruses. In total, 134 of the 534 arboviruses have been reported to cause illness in humans (Refs 7, 8).

Arboviruses have a global distribution but the majority circulate in tropical areas where climatic conditions are favourable for year-round transmission. Arboviruses usually circulate within enzootic cycles involving wild or domestic animals with relatively few human infections (Ref. 9). Birds and rodents are the main reservoir hosts and mosquitoes and ticks are most often the vectors for the most important arboviruses (Table 1). 'Spill-over' of arboviruses from enzootic cycles to humans by enzootic or 'bridge vectors' can occur, under the appropriate ecological conditions. For most arboviruses, humans are deadend or incidental hosts; however, there are several viruses such as dengue, yellow fever and chikungunya that primarily infect people during outbreaks and then begin to use humans as amplification sources (Ref. 9). Figure 1 illustrates the various mechanisms by which humans are infected by zoonotic and nonzoonotic arboviruses (Ref. 10).

$\dagger$ These authors contributed equally to this work.

(C) Cambridge University Press 2016. This is an Open Access article, distributed under the terms of the Creative Commons Attribution licence (http://creativecommons.org/licenses/by/4.0/), which permits unrestricted re-use, distribution, and reproduction in any medium, provided the original work is properly cited. 
TABLE 1.

THE LISTS OF THE MOST IMPORTANT ARBOVIRUSES AND THEIR CHARACTERISATION

\begin{tabular}{|c|c|c|c|c|c|}
\hline Family & Virus/vector & Vertebrate host & $\begin{array}{l}\text { Diseases in } \\
\text { humans }\end{array}$ & Geographic distribution & Vaccine \\
\hline \multirow[t]{9}{*}{ Togaviridae } & $\begin{array}{l}\text { Chikungunya/mosquitoes (Refs } 11 \text {, } \\
\text { 12,13) }\end{array}$ & Humans, Primates & SFI & Arica, Asia, Europe & NO \\
\hline & Ross river/mosquitoes (Refs 13,14) & $\begin{array}{l}\text { Humans, } \\
\text { Marsupials }\end{array}$ & SFI & Australia, South Pacific & NO \\
\hline & Mayaro/mosquitoes (Refs 13,15) & Birds & SFI & South America & NO \\
\hline & O'nyong-nyong/mosquitoes (Ref. 13) & $?$ & SFI & Africa & NO \\
\hline & Sindbis/mosquitoes (Refs 11,13 ) & Birds & SFI & $\begin{array}{l}\text { Asia, Africa, Australia, Europe, } \\
\text { USA }\end{array}$ & NO \\
\hline & Barmah forest/mosquitoes (Ref. 14) & ? & SFI & Australia & NO \\
\hline & $\begin{array}{l}\text { Eastern equine encephalitis / } \\
\text { mosquitoes (Ref. 16) }\end{array}$ & Birds & SFI, ME & USA & YES \\
\hline & $\begin{array}{l}\text { Western equine encephalitis/ } \\
\text { mosquitoes (Ref. 17) }\end{array}$ & Birds, Rabbits & SFI, ME & USA & NO \\
\hline & $\begin{array}{l}\text { Venezuelan equine encephalitis/ } \\
\text { mosquitoes (Ref. 18) }\end{array}$ & Rodents & SFI, ME & USA & YES \\
\hline \multirow{10}{*}{ Flaviviridae } & Dengue $1-4 /$ mosquitoes $(\operatorname{Refs} 19,20)$ & Humans, Primates & SFI, HF & Tropical countries & NO \\
\hline & $\begin{array}{l}\text { Yellow fever/mosquitoes (Refs 19, 21, } \\
\text { 22) }\end{array}$ & Humans, Primates & SFI, HF & Africa, South America & YES \\
\hline & $\begin{array}{l}\text { Japanese encephalitis/mosquitoes } \\
\text { (Refs } 19,23)\end{array}$ & Birds, Pigs & FSI, ME & Asia, Pacific, Australia & YES \\
\hline & $\begin{array}{l}\text { Murray valley encephalitis/mosquitoes } \\
\text { (Refs } 19,24)\end{array}$ & Birds & SFI, ME & Australia & NO \\
\hline & $\begin{array}{l}\text { Rocio encephalitis/mosquitoes } \\
\text { (Ref. 19) }\end{array}$ & Birds & SFI, ME & South America & NO \\
\hline & $\begin{array}{l}\text { St. Louis encephalitis/mosquitoes } \\
\quad(\text { Refs } 19,25)\end{array}$ & Birds & SFI, ME & Americas & NO \\
\hline & West Nile/mosquitoes (Refs 19,26 ) & Birds & SFI, ME & $\begin{array}{l}\text { Africa, Asia, Europe, North } \\
\text { America, Australia }\end{array}$ & NO \\
\hline & $\begin{array}{l}\text { Kyasanur forest disease/ticks (Refs } 19 \text {, } \\
\text { 27) }\end{array}$ & $\begin{array}{l}\text { Primates, Rodents, } \\
\text { Camels }\end{array}$ & SFI, HF, ME & India, Saudi Arabia & YES \\
\hline & $\begin{array}{l}\text { Omsk haemorrhagic fever/ticks } \\
\text { (Refs } 19,28)\end{array}$ & Rodents & SFI, HF & Asia & NO \\
\hline & $\begin{array}{l}\text { Tick-borne encephalitis/ticks (Refs } 19 \text {, } \\
\text { 29) }\end{array}$ & Birds, Rodents & SFI, ME & Europe, Asia, North America & YES \\
\hline \multirow[t]{6}{*}{ Bunyaviridae } & Sandfly fever/sandflies (Ref. 30) & ? & SFI & Europe, Africa, Asia & NO \\
\hline & Rift valley fever/mosquitoes (Ref. 31) & $?$ & SFI, HF, ME & Africa, Middle East & YES \\
\hline & $\begin{array}{l}\text { La Crosse encephalitis/mosquitoes } \\
\text { (Ref. 32) }\end{array}$ & Rodents & SFI, ME & North America & NO \\
\hline & $\begin{array}{l}\text { California encephalitis/mosquitoes } \\
\text { (Ref. 1) }\end{array}$ & Rodents & SFI, ME & North America, Europe, Asia & NO \\
\hline & $\begin{array}{l}\text { Congo-Crim. haemorrhagic } \\
\text { encephalitis/ticks (Refs 20,33) }\end{array}$ & Rodents & SFI, HF & Europe & YES \\
\hline & Oropouche fever/midges (Refs 19,34 ) & $?$ & SFI & Central and South America & NO \\
\hline Reoviridae & $\begin{array}{l}\text { Colorado tick fever virus/ticks } \\
\text { (Ref. 35) }\end{array}$ & Rodents & SFI & North America & No \\
\hline
\end{tabular}

HF, haemorrhagic fever; ME, meningoencephalitis; SFI, systematic febrile illness.

Arboviruses have been causing human disease for at least a thousand years but during recent decades some have newly emerged or re-emerged and a few have increased in importance because of human population expansion and increased urbanization, increased trade or travel and global climate change (Refs 2, 9, 36). Arthropod-borne viruses have been a serious public health concern, with viruses such as dengue (DEN) and yellow fever viruses causing millions of infections annually, while emerging arboviruses, such as West Nile, Japanese encephalitis (JE) and Chikungunya viruses (CHIKV) have significantly increased their geographical ranges in recent years (Refs 9, 37, 38, 39).

From a public health point of view, those arboviruses that produce viremia in humans and cause major mosquito-borne epidemics are most important (Ref. 40).
Figure 2 shows world geographical distribution of the most important vector-born arboviruses. In the following section we will discuss some of the most common arbovirus-induced diseases.

\section{Common arbovirus-induced diseases}

\section{Dengue/dengue haemorrhagic fever}

The dengue viruses (DENV) are the only arboviruses that are fully adapted to the human host and its environment, thus eliminating the need for an enzootic transmission cycle (Refs 52, 53). Consequently, in recent years, transmission has increased in urban and semiurban areas and has caused a major international public health concern (Refs 54, 55). DEN is now endemic in more than 100 countries in Africa, the 


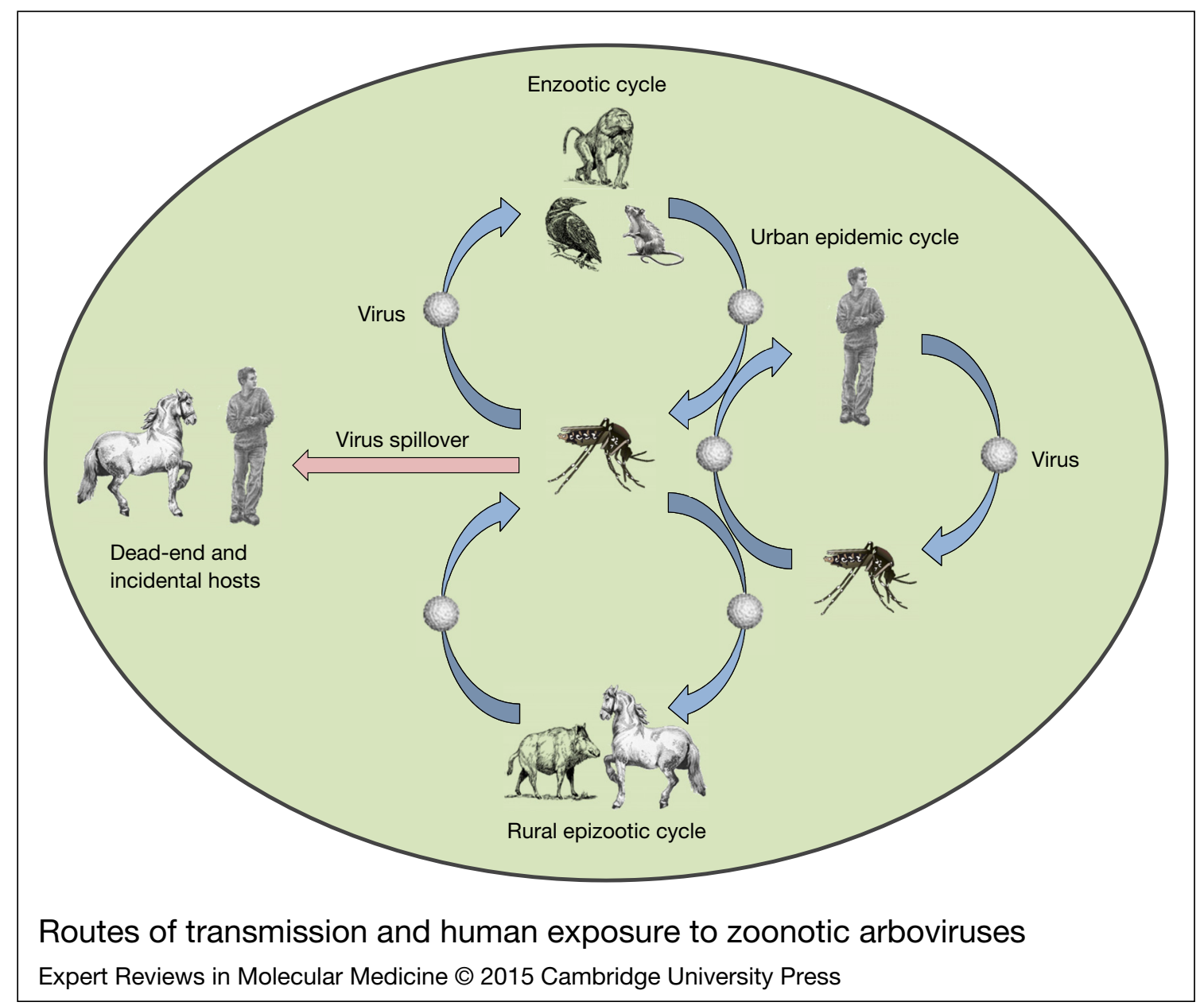

FIGURE 1 .

Routes of transmission and human exposure to zoonotic arboviruses. Infectious agents may be transmitted to humans by direct contact with infected animals, mechanical vectors or intermediate hosts. Arboviruses are maintained in mosquito-monkey, mosquito-rodent, mosquitobird, mosquito-pig, mosquito-horse and mosquito-human cycles. The enzootic cycle occurs in the region where humans intrude into the natural foci of infection. The rural epizootic cycle is involved among domestic animals and mosquitos, and amplified in the presence of intermediate hosts, which result in representing a large reservoir of viruses and severe spillover effect to dead-end hosts. In urban settings, viruses are transmitted between humans and the mosquito vectors in an urban epidemic cycle, using humans for amplification (Ref. 10).

USA, the Eastern Mediterranean, South-east Asia and the Western Pacific (Ref. 41). Severe DEN, previously known as Dengue haemorrhagic fever, occurs primarily in Asian and Latin American countries and has been a leading cause of hospitalization and death among children in these countries (Ref. 42). About 1.6 million cases of $D E N$ were documented in the USA alone in 2010 (Ref. 42). The incidence of DEN has increased dramatically in recent years with over 2.5 billion people now at risk of contracting $D E N$ (Ref. 56). It has been estimated that the annual number of $D E N V$ infections could be from 50 to 400 million cases with 25000 deaths reported annually (Ref. 56).

Female Aedes aegypti mosquitoes can take blood meals from multiple human hosts during each feeding period, which increases the chance of infecting many human hosts (Ref. 42). Aedes albopictus acts as a secondary vector of $D E N V$ in Asia, and has recently expanded its geographical distribution both into and within parts of North America and Europe. Infection with $D E N V$ can be asymptomatic but often patients present with high fever, headache, pain behind the eyes, muscle and joint pains, nausea, vomiting, swollen glands or rash (Ref. 42). Severe DEN can potentially cause death because of plasma leakage, fluid accumulation, respiratory distress, severe bleeding or organ impairment (Ref. 42). There is no vaccine or treatment against this virus; therefore, environmental management, mosquito control and personal protection have been recommended (Ref. 56).

\section{Yellow fever}

Yellow fever is a well-known disease that has caused major epidemics in the USA and Africa over the last four centuries (Ref. 1). It is endemic to parts of Africa and was introduced, along with its vector Ae. aegypti, into the Western Hemisphere in the early 1600s (Ref. 57). Globally over 900 million people are living in regions where Yellow fever is endemic and it is estimated that 200000 cases of Yellow fever occur, resulting in 30000 deaths each year (Ref. 43). 


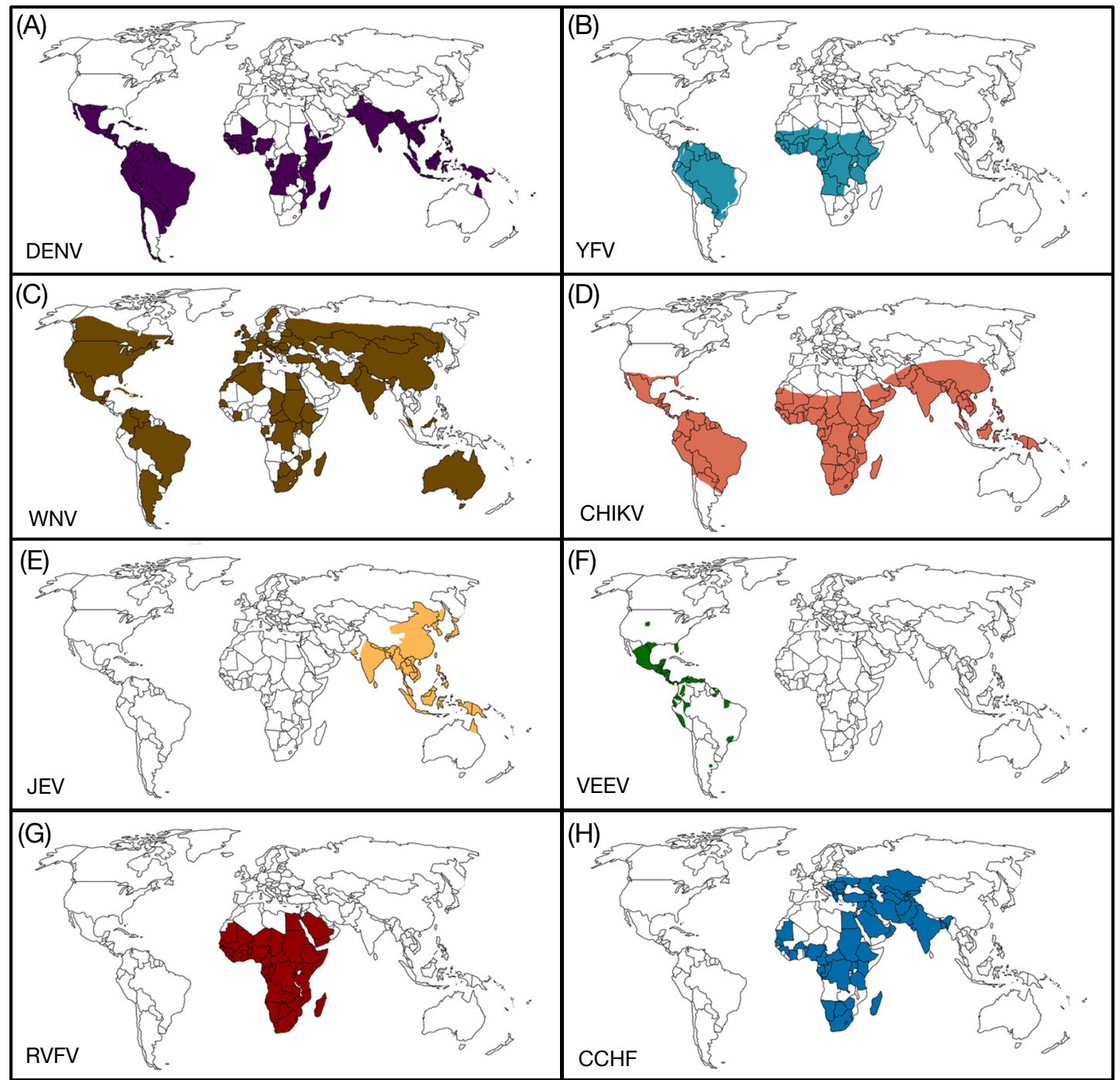

\section{Global distribution of some of the most important arboviruses}

Expert Reviews in Molecular Medicine @ 2015 Cambridge University Press

FIGURE 2.

Global distribution of some of the most important arboviruses. (A) DENV, Dengue virus (Refs 41, 42), (B) YFV, Yellow fever (Refs 43, 44), (C) WNV, West Nile virus (Refs 45, 46, 47), (D) CHIKV, Chikungunya virus (Refs 47, 48), (E) JEV, Japanese encephalitis virus (Ref. 49), (F) VEEV, Venezuelan equine encephalitis virus (Ref. 47), (G) RVFV, Rift valley fever virus (Ref. 50), (H) CCHF, Crimean-Congo haemorrhagic fever (Ref. 51).

There are no specific anti-viral treatments for Yellow fever, and the primary interventions are supportive care. Vaccination is the most important strategy to prevent Yellow fever. The current vaccine is highly effective and provides immunity within 30 days for $99 \%$ of vaccinated people (Refs 43,44 ).

\section{West Nile virus}

West Nile virus ( $W N V$ ) was reported for the first time in Uganda in 1937 and then disappeared until the 1950s when it became widespread and caused disease outbreaks in the Middle East, India and Israel (Refs 1). $W N V$ was recognized in the Western Hemisphere in the Northeastern USA in 1999 (Refs 52, 58, 59). In
2001, it became more widespread and 66 human cases with 9 deaths were reported from 10 states (Refs 44, $60,61)$. In August 2001, $W N V$ was identified in birds from Ontario, Canada (Ref. 62). The introduction of $W N V$ into the USA has had a significant public health and economic impact. Millions of dollars have been spent on rebuilding and improving public health facilities to implement surveillance, prevention and control programs against $W N V$ and other arboviral pathogens (Refs 63, 64). Currently, there is no human vaccine for $W N V$ although several are available for horses (Ref. 52). Prevention and control is accomplished through effective surveillance coupled with targeted preventive measures and mosquito control (Ref. 1). 


\section{Japanese encephalitis}

Japanese encephalitis virus (JEV) is a Flavivirus that is maintained in an enzootic cycle involving Culex species of mosquitoes and aquatic birds (Refs 19, 23, 65). Pigs are efficient amplification hosts and their involvement greatly increases the risk of infection in humans (Ref. 65). Children are particularly susceptible to $J E V$ infections and humans and horses are incidental hosts that can suffer a significant level of illness and death (Ref. 65). JEV is considered a leading cause of viral encephalitis worldwide, with more than 40000 cases in Asia alone (Refs 66, 67). Climate, geography and host immune status play a significant role in $J E V$ epidemiology (Refs 1, 68). JEV has been considered an emerging disease in the Indian subcontinent, parts of Southeast Asia and in the Pacific, and it caused a major epidemic in India for the first time in 1995 (Refs 69, 70, 71). JEV has also become a major public health problem in Nepal (Refs 72, 73, 74). It is possible that $J E V$ has become established in northern Australia and possibly in other regions such as the USA where hosts and vectors are present (Ref. 47). Vaccination and changes in agricultural and animal husbandry practises are considered effective in controlling this arbovirus (Refs 52, 75).

\section{Rift valley fever}

Rift valley fever virus (RVFV) has been responsible for numerous outbreaks of severe disease in domestic livestock (cattle, goats, camels and sheep) and humans over the past 70 years (Refs 76, 77). This virus was responsible for an outbreak affecting an estimated 200000 people and devastated the sheep industry in Egypt from 1977 to 1979 (Refs 31, 78). It has now been reported in Saudi Arabia and Yemen (Refs 79, 80, 81 ), and recent outbreaks have occurred in Kenya, Tanzania and South Africa (Refs 82, 83). Concerns have been raised regarding the agricultural and medical impact that this zoonotic disease agent might have if it were to continue to expand its geographic range, either by natural means or intentional release (Refs 84, 85, 86, 87). Based on the outcome of the previous outbreaks, the threat from $R V F V$ must not be underestimated as the consequences of this virus are dramatic, both for humans and livestock (Ref. 31).

\section{Venezuelan equine encephalitis}

Venezuelan equine encephalitis (VEE) is an Alphavirus that has been isolated from a variety of animals including horses, rodents and mosquitoes (Refs 88, 89, 90). The geographic range of $V E E$ virus is from Argentina to the USA. VEE virus includes five serotypes; two serotypes, $\mathrm{AB}$ and $\mathrm{C}$, are considered epizootic and are pathogenic for horses (Refs 88, 89, 90), while the three serotypes D, E and F are considered to be enzootic. Both epizootic and enzootic variants of VEE virus cause a nonspecific viral syndrome in humans (Refs 89, 90). Epizootic virus infection can develop into encephalitis in a small number of cases. Death can occur following infection with either enzootic or epizootic serotypes of $V E E$ virus (Ref. 1). VEE virus causes illness with symptoms similar to dengue and other mosquito-borne arboviruses; therefore, the numbers of reported cases may be an underestimate (Ref. 18). There is no treatment for this disease and also no licenced human vaccine for this virus except a live-attenuated vaccine for military forces and laboratory personnel (Ref. 91).

\section{Viruses and autophagy, apoptosis and unfolded protein response (UPR)}

Many viruses hijack host cell responses for their own benefit and use them as complementary mechanisms for replication and infection. Some of the most important host mechanisms that are usually affected by viral infection are pathways involved in cell death and cellular responses against environmental stress. These mechanisms include apoptosis (i.e. programmed cell death I), autophagy (programmed cell death II) and UPR. These mechanisms play essential functions in regulating cell fate and are important for normal cellular functions. In addition, these mechanisms are tightly regulated and can affect each other. They are usually interconnected and also 'cross-talk' with each other. We will briefly review the general concepts of apoptosis, autophagy and UPR and explain their cross-talk and regulatory mechanisms. We will then focus on the role of apoptosis, autophagy and UPR in arbovirus replication and infection and then describe different possible therapeutic approaches for arboviruses by discussing the involvement of apoptosis, autophagy and how they may determine therapeutic strategies.

\section{An overview of autophagy, apoptosis and UPR}

\section{Autophagy}

Lysosomes are the final destination for degradation of long-lived and dysfunctional cellular components through autophagy, a highly regulated catabolic process. This process is essential for maintaining cellular integrity, homeostasis, survival, differentiation and development (Refs 92, 93, 94, 95). In mammals, the role of nutrient deprivation, hormonal stimuli, including glucagon and insulin, and other autophagy activation cues such as temperature, oxygen concentration and cell density have been elucidated (Refs 96, 97, 98, 99). There are three different types of autophagy, all of which differ in their mechanisms and functions: chaperone-mediated autophagy (CMA), microautophagy and macroautophagy (Refs 100, 101, 102, 103, 104, 105). During CMA, specific cytosolic proteins are selectively tagged by the CMA substrate chaperone complex and then moved to the lysosome for degradation (Refs 104, 106, 107). This is the only form of autophagy in which no vesicular traffic is involved (Ref. 108). Microautophagy directly targets small 


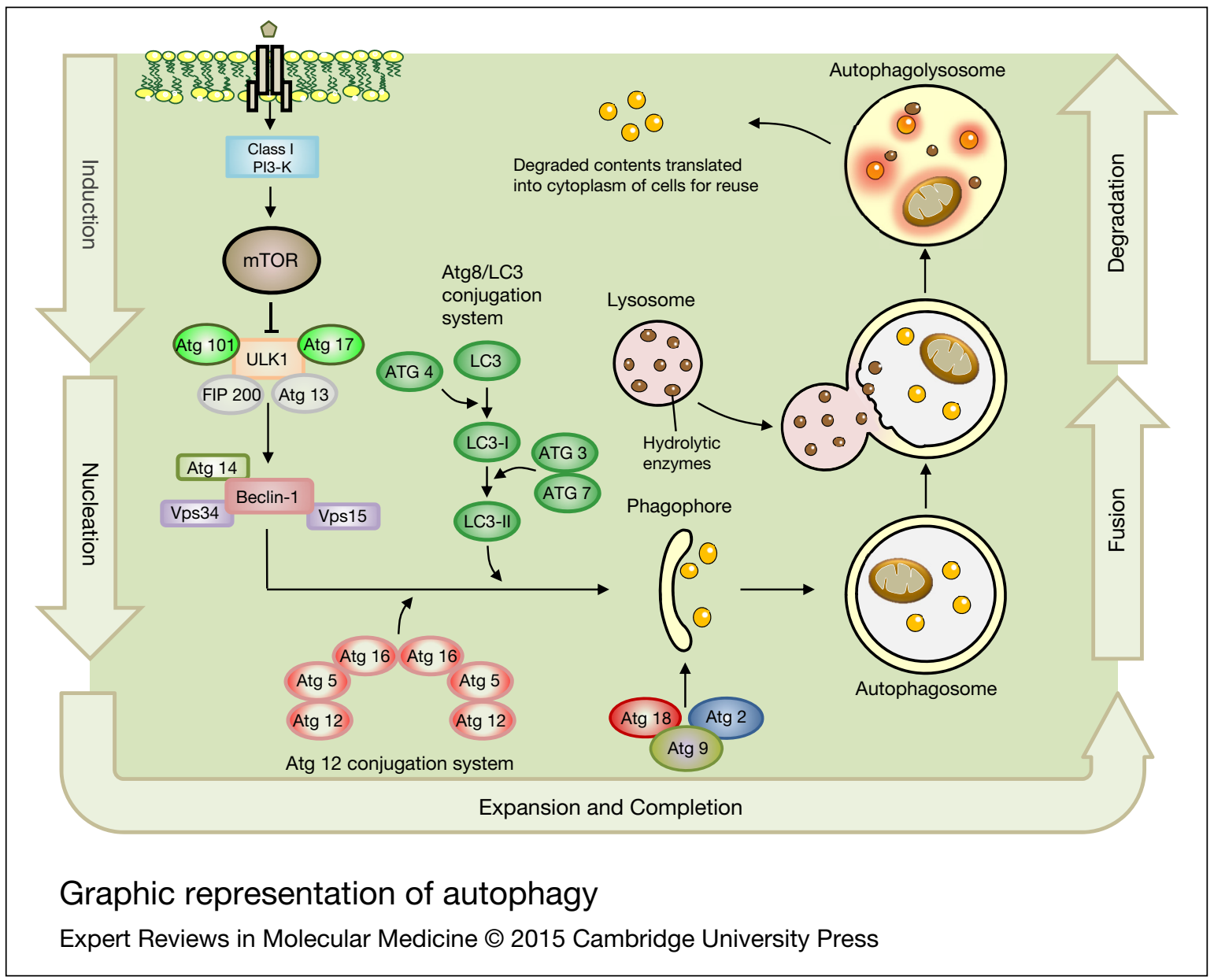

FIGURE 3

Graphic representation of autophagy. Autophagy is a process for the degradation and recycling of damaged or unnecessary cellular compartments, which has several tightly regulated steps including induction, nucleation, expansion and completion, fusion and degradation. The mTOR is known as the key regulator of autophagy induction and can be suppressed by ULK1, leading to trigger VPS34-Beclin 1-class III PI3-kinase complex. Several different membrane pools contribute to the formation of the phagophore. The Atg proteins (Atg2, Atg9, Atg18) are essential for phagophore formation. The ATG and LC3 conjugation system also contribute in autophagosome membrane formation and elongation. The autophagolysosome then is formed by fusion of the autophagosome with a lysosome to degrade and reuse the compounds. ATG, autophagyrelated genes; mTOR, mammalian target of rapamycin.

proteins and organelles using lysosomes (Refs 109, $110,111)$. However, macroautophagy is the major regulated catabolic mechanism by which the bulk of damaged cytoplasmic proteins and organelles are sequestered within an autophagosome (Refs 112, 113, 114). In this review, we will focus on macroautophagy (referred to herein as 'autophagy').

The first step in autophagy (see Fig. 3) involves formation and expansion of a double-membrane structure, which is called the 'isolation membrane' or 'phagophore'. The edges of this membrane eventually fuse to form a new double membrane-bound vacuole, known as the autophagosome that sequesters the cytoplasmic cargo. The autophagolysosome is formed by fusion of the autophagosome with a lysosome and lysosomal contents are degraded by hydrolytic enzymes (Refs 115, 116, 117, 118). As a result of degradation, nucleotides, amino acids and free fatty acids (FFAs) are generated and then reused for energy metabolism, macromolecular production and biosynthesis (Refs 119, 120).
It is assumed that the different steps in macroautophagy are mediated by autophagy-related genes (ATG), which encode proteins involved in autophagy (Refs 121, 122). These proteins have been classified into five different functional categories: (i) a protein serine/threonine kinase complex that responds to upstream events such as target of rapamycin (TOR) kinase (Atg1/ULK1, Atg13 and Atg17); (ii) a lipid kinase group that controls vesicle nucleation (Atg6/Beclin1, Atg14, Vps34/ PI3KC3 and Vps15); (iii) two ubiquitin-like conjugation pathways that stimulate vesicle expansion (the Atg8 and Atg12 conjugation systems); (iv) a recycling pathway that is required for disassembly of Atg proteins (Atg2, Atg9, Atg18); and (v) vacuolar permeases that permit the efflux of amino acids from the degradative compartment (Atg22) (Refs 93, 119). The mammalian TOR (mTOR) kinase acts as a negative regulator of autophagy and is a central controller of cell growth, aging and proliferation (Refs 123, 124). Under starvation conditions, inhibited mTOR induces autophagy through 
phosphorylation of the Ulk1-Atg13-FIP200-Atg101 complex (Refs 125, 126), leading to localization of Ulk1/2 and Atg13 to the autophagic isolation membrane (Refs 127, 128). During the initiation step of autophagy, Beclin 1 interacts with Vps34, which contributes to Atg protein recruitment and autophagosome nucleation (Refs 129, 130). Interaction with various Beclin-1-interacting proteins facilitates the coordination of these events (Ref. 131). LC3, the mammalian ortholog of Atg8, is cleaved by Atg 4 and then conjugated to the polar head of phosphatidylethanolamine (PE) to generate LC3-II, which is necessary during the elongation step of autophagy (Refs 132, 133). Hence, the autophagosome is regulated in response to the Beclin-1/Vps34/UVRAG complex, known as the maturation step (Refs 134, 135, 136). An overview of autophagy is summarised in Figure 3.

\section{Apoptosis}

There are two main functionally distinct pathways for apoptosis induction (Fig. 4): the extrinsic and the intrinsic mitochondrial pathways (Refs 137, 138, 139). Caspases are involved in most of the apoptotic processes and are activated by ligation of death receptors [tumour necrosis factor receptor (TNFR), Fas, TNF-related apoptosis-inducing ligand (TRAIL)] or release of specific proteins from the mitochondria (Refs 140, 141). However, accumulating evidence suggests that the two pathways are intimately intertwined (Refs 138, 142), which will be described in the next sections. The extrinsic apoptosis cascade is stimulated after the binding of cell surface receptors to their ligands, resulting in Fas-associated protein with death domain (FADD)-dependent activation of initiator caspases, namely caspase- 8 , and subsequently caspase- 3 and -7 (Refs 143, 144). As a consequence, effector caspases (i.e. caspase- 3 and caspase-7) are dimerized and activated and, once active they can cause apoptosis (Refs 141, 145).

The mitochondrial apoptotic death mechanism integrates various extracellular stimuli including drugs, nutrients and radiation and also different intracellular stimuli such as oxidative stress, oncogene expression, endoplasmic reticulum (ER) stress and DNA damage (Refs 146, 147). The apoptotic signals in this pathway converge on the mitochondria to release apoptogenic proteins such as cytochrome c, apoptosisinducing factor (AIF), Smac/DIABLO, Omi/HtrA2 and mitochondrial endonuclease G (Refs 148, 149, $150,151)$. The Bcl-2 family of proteins serve as important regulators of the release of these mitochondrial proteins that can be divided into two classes: (i) antiapoptotic members (e.g. Bcl-2 and Bcl-xL); and (ii) proapoptotic members (e.g. Bax, Bak, Bid, Bad, Noxa, Puma and others) (Refs 152, 153). Up-regulation of proapoptotic proteins or down-regulation of antiapoptotic proteins can cause an increase in permeability of the mitochondrial membrane, which later promotes release of cytochrome $\mathrm{c}$ and other proteins into the cytosol (Refs 151, 154, 155, 156). In the presence of deoxyadenosine triphosphate (dATP), the released cytochrome c interacts with Apaf-1 and caspase-9 and forms a ternary complex, leading to activation of caspase- 3 and then apoptosis (Refs 142, 157, 158). In addition, p53 plays a stimulating role in intrinsic apoptosis induction (Refs 159, 160, 161). Thus, the two direct p53 transcriptional targets Noxa and Puma can mediate the pro-apoptotic activity of Bax and Bak, and thereby promote apoptosis (Refs 162, 163).

It is widely accepted that there is cross-talk between the two extrinsic and intrinsic pathways, such that activity in one pathway interferes with signalling steps in the other pathway (Ref. 141).

The pro-apoptotic cytochrome c-releasing factor Bid is positioned to serve as a link between the extrinsic death receptor pathway and the intrinsic pathway (Ref. 154). Cleavage of the BID protein in the cytoplasm by caspase- 8 causes Bid to localise in the cytosol while truncated Bid translocates to the mitochondria and activates the mitochondrial pathway after apoptosis induction through death receptors, and can be used to amplify the apoptotic signal (Ref. 164). Although Bid is a downstream target of caspase- 8 in the extrinsic apoptotic pathway, it also acts as ligand for Bax and Bak, causing caspase-9 activation (Refs 154, 165). Caspase-9 activation proteolytically activates downstream caspases (e.g. caspases-3,-6,-7), which, in turn, can result in apoptosis (Refs 166, 167).

\section{$U P R$}

The ER contains an extensive network of tubules, sacs and cisternae, which extend from the cell plasma membrane through the cytoplasm and to the nuclear envelop through a continuous connected network (Refs 168, 169). The ER is the main sub-cellular compartment involved in proper folding of proteins and their maturation. Approximately one-third of the total proteins are synthesised in the ER. Many different perturbations can alter the function of the ER leading to unfolding or misfolding of proteins in the ER. This condition is referred to as ER stress (Refs 169, 170). The ER creates a series of adaptive mechanisms to prevent cell death complications and these together are referred to as the UPR (Refs 170, 171). The UPR can be involved in the secretory pathway leading to restoration of protein folding homeostasis. However, if there is too much stress on the ER, and the ER cannot cope with this stress, it will eventually lead to cell death (Ref. 172). The UPR also plays an important role in maintaining cellular homeostasis of specialised secretory cells such as pancreatic beta cells, salivary glands and plasma B cells (Ref. 170). It is becoming increasingly evident from animal models that UPR has several functions that are not directly linked to protein folding including inflammation, energy control and lipid and cholesterol metabolism (Ref. 170). The existence of UPR was first reported by Kozatsumi et al. more than 25 years ago 


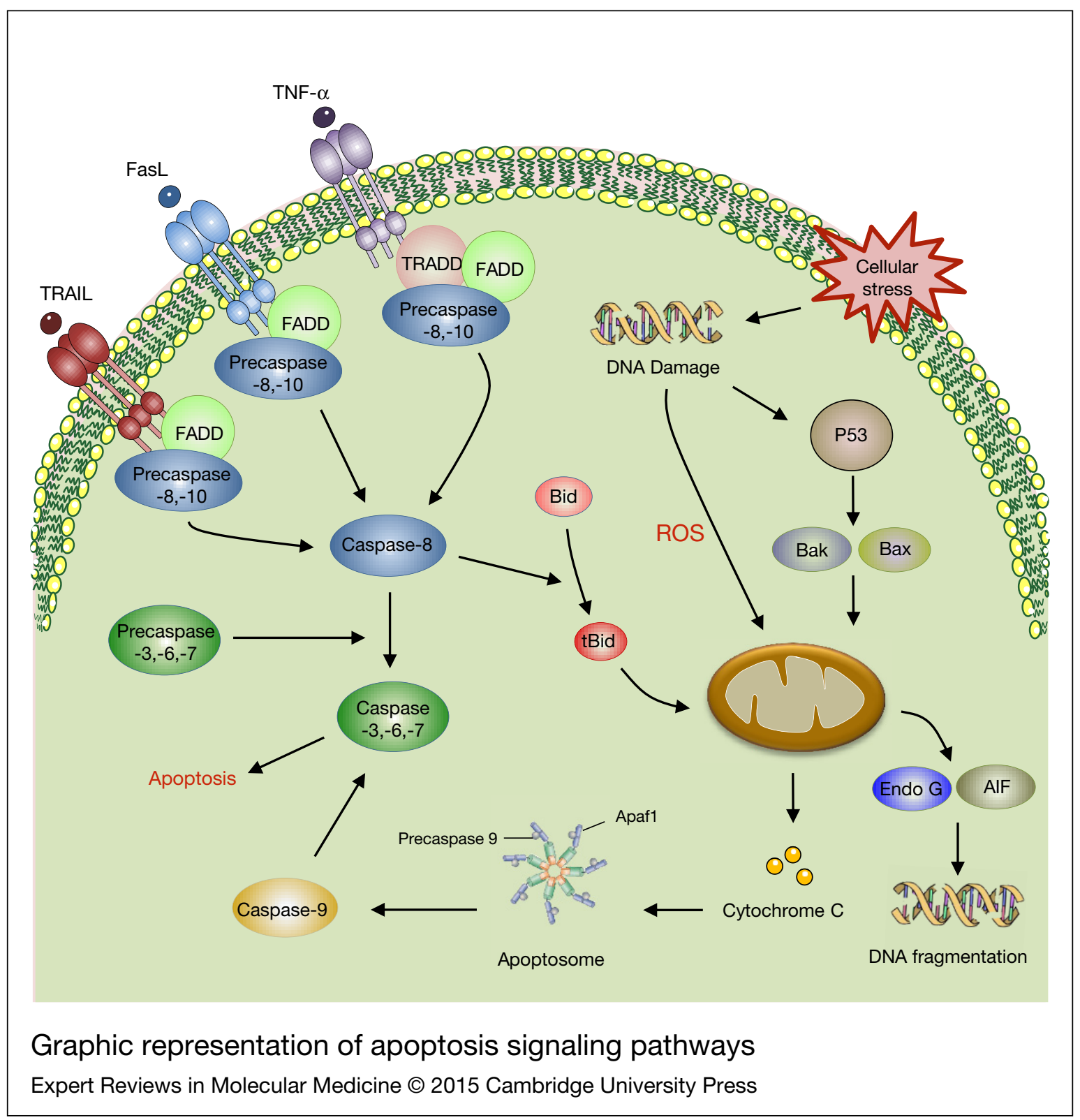

FIGURE 4

Graphic representation of apoptosis signalling pathways. Apoptosis is initiated via two different routes including extrinsic and intrinsic apoptotic pathways. The extrinsic signals are initiated by cell death ligands (e.g. FasL, APO-2L, TRAIL, TNF) and activate FADD and subsequently cleave pro-caspase-8. Cleavage of pro-caspases- 8 and -10 initiate activation of caspases- 8 and -10 , which later can directly trigger effector caspases including caspases-3, -6 and -7 . The intrinsic pathway is stimulated via DNA damage. Once DNA damage occurs, p53 is activated and induces apoptosis in a mitochondria-dependent manner. In this pathway, pro-apoptotic and antiapoptotic proteins are up- and down-regulated, leading to release of cytochrome c. Released cytochrome c later can activate caspase 9 which in turn activates caspase-3. FasL, Fas (Apo-1/ CD95) ligand; TNF, tumour necrosis factor receptor TRAIL, TNF, tumour necrosis factor receptor.

(Ref. 173). They showed that glucose regulated proteins (GRPs) that are associated with the ER are upregulated upon sensing the presence of unfolded or misfolded proteins in the ER (Ref. 173). While the mechanisms and signalling events behind it were not known at the time, today we have a much better understanding of the UPR and how these events are regulated in the ER at the molecular level. ER stress response signals are constantly monitored by three main classes of sensors. These include inositol requiring enzyme 1 alpha (IRE-1 $\alpha$ ) and IRE-1 $\beta$, protein kinase RNA like ER kinase (PERK) and activating transcription factor 6
(ATF6; both $\alpha$ and $\beta$ isoforms) (Fig. 5). In normal healthy cells these sensors are in an inactive state.

IRE1. This is a type I transmembrane protein receptor having an N-terminal ER luminal-sensing domain. The cytoplasmic C-terminal region contains both an endoribonuclease domain and a Ser/Thr kinase domain (Ref. 169). There are two homologues of IRE1: IRE1 $\alpha$ and IRE1 $\beta$. Activation of IRE1 involves dissociation from Grp78, followed by dimerization, oligomerization and trans-autophosphorylation, which leads to conformational changes and activation of its 


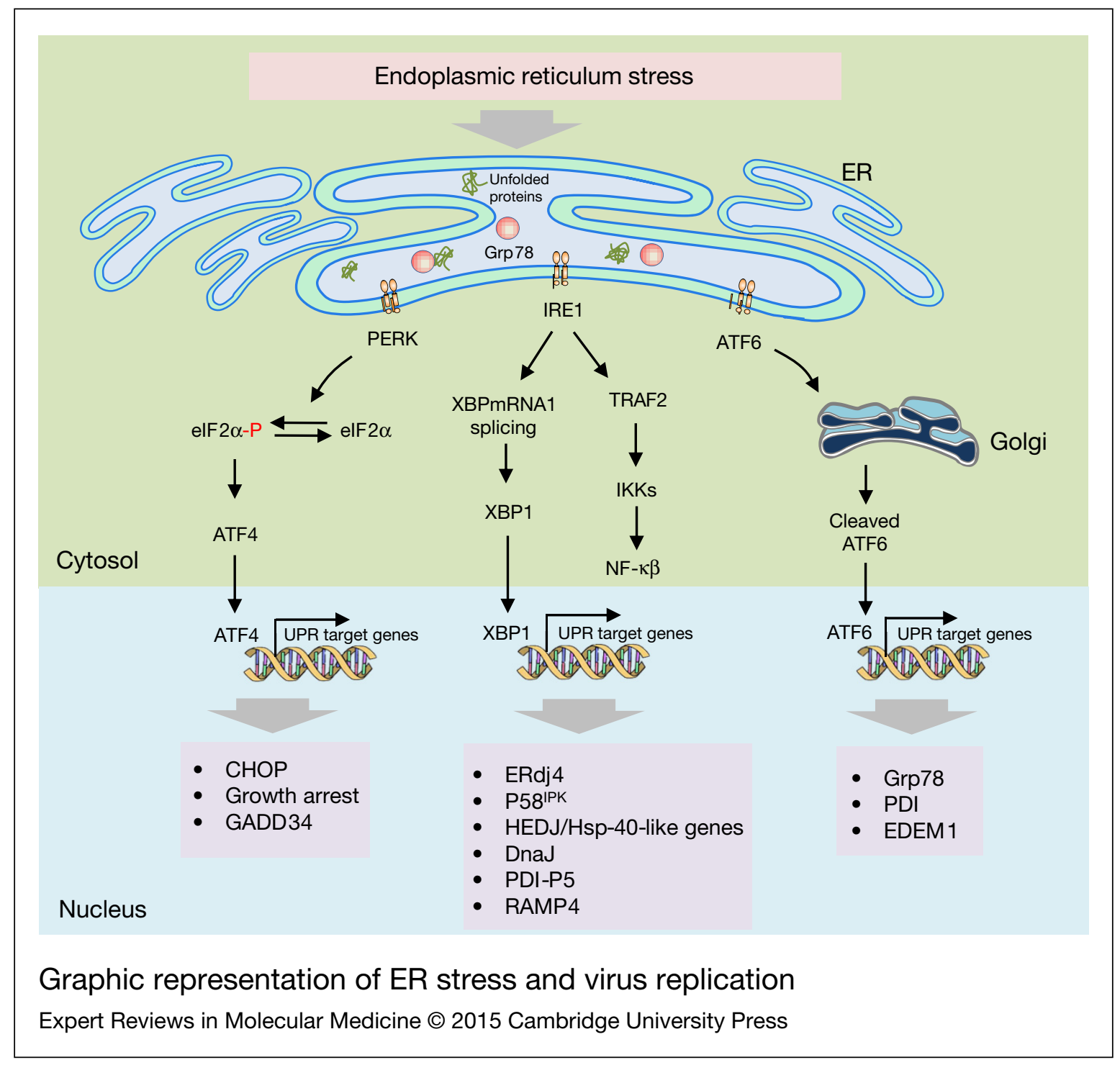

FIGURE 5 .

Graphic representation of ER stress and virus replication. ER stress is enhanced in the viral infected cells and activates UPR proteins (e.g. PERK, ATF6, and IRE1). Activated PERK leads to induce ATF4 via phosphorylation of eIF2a, causing attenuation of translation and inducing genes encoding CHOP. Upon IRE1 activation, TRAF2 and sXBPmRNA1 splicing are initiated in the cytoplasm, subsequently leading to activation of UPR target genes. The degradation of ATF6 is increased through recruitment of ATF6, a UPR sensor. ATF6 translocates to the Golgi and is cleaved to a nucleus targeting form that promotes expression of UPR-responsive genes. The consequences of UPR activation are necessary for viral replication and pathogenesis. ATF, activating transcription factor; CHOP, C/EBP homologous protein; ER, endoplasmic reticulum; IRE1, inositol-requiring enzyme; PERK, protein kinase RNA like ER kinase; UPR, unfolded protein response.

RNase domain (Ref. 170). Activated IRE1 excises a 26-nucleotide intron region from mRNA that encodes the transcription factor X-box binding protein 1 (XBP1). Dissociation of this 26-nucleotide intron region from XBP1 leads to a shift in the coding reading frame and produces a more stable form of XBP1 called XBP1 spliced form (XBP1s) (Ref. 170). IRE1-XBP1s signalling axis modulates pro-survival responses by targeting many genes involved in protein folding, maturation and ER-associated degradation (Ref. 169). XBP1 also modulates phospholipid synthesis which is required for ER expansion under ER stress (Ref. 174). Some examples of XBP1 target genes include ERdj4, P58 ${ }^{\mathrm{IPK}}$, human ER-associated DNAJ (HEDJ), DnaJ/Hsp-40-like genes and protein disulphide isomerase (PDI) P5 (PDI-P5) and ribosome associated membrane protein 4 (RAMP4) (Ref. 169). Different studies have shown that activation of IRE1 signalling is robust at first but as time progresses it diminishes (Refs 169, 175). However, artificial maintenance of IRE1 signalling is achieved by a chemically-activated mutant form of IRE1, which is positively correlated with enhanced cell survival conditions under ER stress, suggesting that IRE1 signalling mainly plays a role in a pro-survival pathway (Refs 169, 175, 176).

ATF6. ATF6 is a type II transmembrane protein that contains a basic leucine zipper (bZIP) transcription factor domain in its cytosolic terminus (Refs 169, 
177). The ATF6 family of ER transducers include ATF6 $\alpha$, ATF6 $\beta$, old astrocyte specifically induced substance (OASIS), LUMAN (also called CREB3), BBF2 human homolog on chromosome 7 (BBF2H7), cyclic-AMP responsive element binding protein hepatocyte (CREBH) and CREBP4 (Ref. 174). Unlike IRE1, ATF6 does not undergo oligomerization, dimerization and autophosphorylation. Under ER stress conditions, Grp78 dissociate from ATF6 thus uncovering the Golgi localisation signal of ATF6. Activated ATF6 translocates into the Golgi complex where it undergoes cleavage by site- 1 and site- 2 proteases (Ref. 177). Thus, the ATF6 N-terminal cleavage product translocates to the nucleus and regulates the expression of genes that are associated with the ER-associated protein degradation pathway. Some of the ATF6 target genes include Grp78, PDI and ER-degradation enhancing-a-mannosidase-like protein 1 (EDEM1). All these proteins work closely to reduce unfolded proteins in the ER lumen (Ref. 169). ATF6 also activates pro-survival transcription factor and IRE1 target gene XBP1 (Refs 178, 179). Similar to that of IRE1 signalling, ATF6 is activated by the UPR but is not sustained throughout the UPR response. ATF6 signalling is primarily for pro-survival but in some cases, ATF6 signalling activates the pro-apoptotic transcription factor $\mathrm{C} /$ EBP homologous protein (CHOP) during prolonged ER stress (Ref. 178).

PERK. This is a type I ER transmembrane protein having an ER luminar sensor domain and a cytoplasmic domain. The cytoplasmic domain contains Ser/ Thr kinase activity. Upon activation by UPR, PERK dissociates itself from Grp78 and undergoes dimerization and trans-auto phosphorylation (Refs 169, 172, 180). Activated PERK phosphorylates eukaryotic translation initiation factor $2 \alpha$ (eIF2 $\alpha$ ). PERK-mediated phosphorylation of Ser51 in eIF $2 \alpha$ reduces the activity of eIF $2 \alpha$ complex and leads to the inhibition of protein synthesis. This rapidly reduces the number of proteins entering the ER and this can lead to a pro-survival effect on the cell (Refs 170, 172, 181). Phosphorylation of eIF $2 \alpha$ also allows translation of mRNAs containing short open reading frames in their $5^{\prime}$ UTR regions. Such translated proteins include activating transcription factor 4 (ATF4) (Ref. 170). ATF4 controls expression of many proteins involved in redox processes and amino acid metabolism, and it modulates the expression of ER chaperones and foldases (Ref. 170). ATF4 also regulates important genes involved in ER apoptosis such as CHOP and growth arrest and DNA damage inducible 34 (GADD34) (Ref. 170). GADD34 is involved in a feedback loop to dephosphorylate eIF $2 \alpha$ by protein phosphatase IC (PPIC) to restore protein synthesis (Refs 170, 182). Another substrate for activated PERK is nuclear factor (erythroid-derived 2 factor)-related factor (Nrf2). In normal cells, Nrf2 is present in the cytoplasm in association with cytoskeletal anchor kelch-like Ech-associated protein (KEAP1). Upon activation PERK phosphorylates
Nrf2 and this helps Nrf2 to dissociate from KEAP1 and translocate into the nucleus (Refs 169, 183). Upon translocation into the nucleus Nrf2 induces the expression of genes that have an anti-oxidant response element (ARE) within their promoter such as heme oxygenase 1 (HO-1), aiding in protein folding and helping to restore ER homeostasis (Refs 169, 183). The role of Nrf2 as a pro-survival factor is further shown by the fact that cells devoid of Nrf2 display increased sensitivity to cell death via apoptosis after ER stress (Refs 169, 183). The overall UPR signalling pathway is shown in Figure 5.

\section{The role of autophagy in arbovirus replication}

Although autophagy was initially proposed as a physiological cellular response to environmental stress followed by virus amplification, increasing evidence now indicates that several viruses may use autophagy as a survival strategy to support their life cycle, which is known as 'pro-viral autophagy' (Refs 131, 138, 184, 185) (Fig. 6). Virus-induced induction of autophagy seems to be associated with replication/ translation of many arboviruses like DENV, JEV, CHIKV, rotavirus, and epizootic haemorrhagic disease virus (EHDV, an orbivirus) (Refs 186, 187, $188,189,190,191)$. The results that were obtained by monitoring LC3 lipidation in $J E V$-infected NT-2 cells, a pluripotent human testicular embryonal carcinoma cell line treated with Rapamycin and 3-methyladenine, revealed that there was a direct relationship between autophagy and viral replication The results were confirmed using an Atg5/Beclin-1 knock down model (Ref. 187). Most commonly, in many eukaryotic cells, it is apparent that the initiation of autophagy can be enhanced in infected $D E N V$ cells; in addition, the replication of $D E N V$ is positively linked to autophagy induction (Ref. 192). However, $D E N V$ viral replication has been shown to be limited in monocytes, which suggests a possible cell-specific relationship between activated autophagy and $D E N V$ production (Ref. 193). $W N V$ induces autophagy even though its replication is autophagy independent (Ref. 194). The importance of virus-induced autophagy and up-regulation of viral replication has also been shown in $C H I K V$-infected cells (Ref. 188). The Orbivirus EHDV induces autophagy, apoptosis and c-Jun N-terminal kinase (JNK) activation, and phosphorylates c-Jun, all of which seem to benefit viral replication (Ref. 190). JEV also induces autophagy in the early stage of infection and the inoculated viral particles traffic to autophagosomes for subsequent steps of viral infection (Ref. 187). In vivo studies showed that autophagy played a supporting role in $D E N V-2$ replication and pathogenesis (Ref. 195).

Although the function or functions of autophagy in promoting virus replication are not completely understood, experimental evidence suggests that there are multiple autophagy pro-viral mechanisms, including serving as a scaffold for viral replication, contributing 


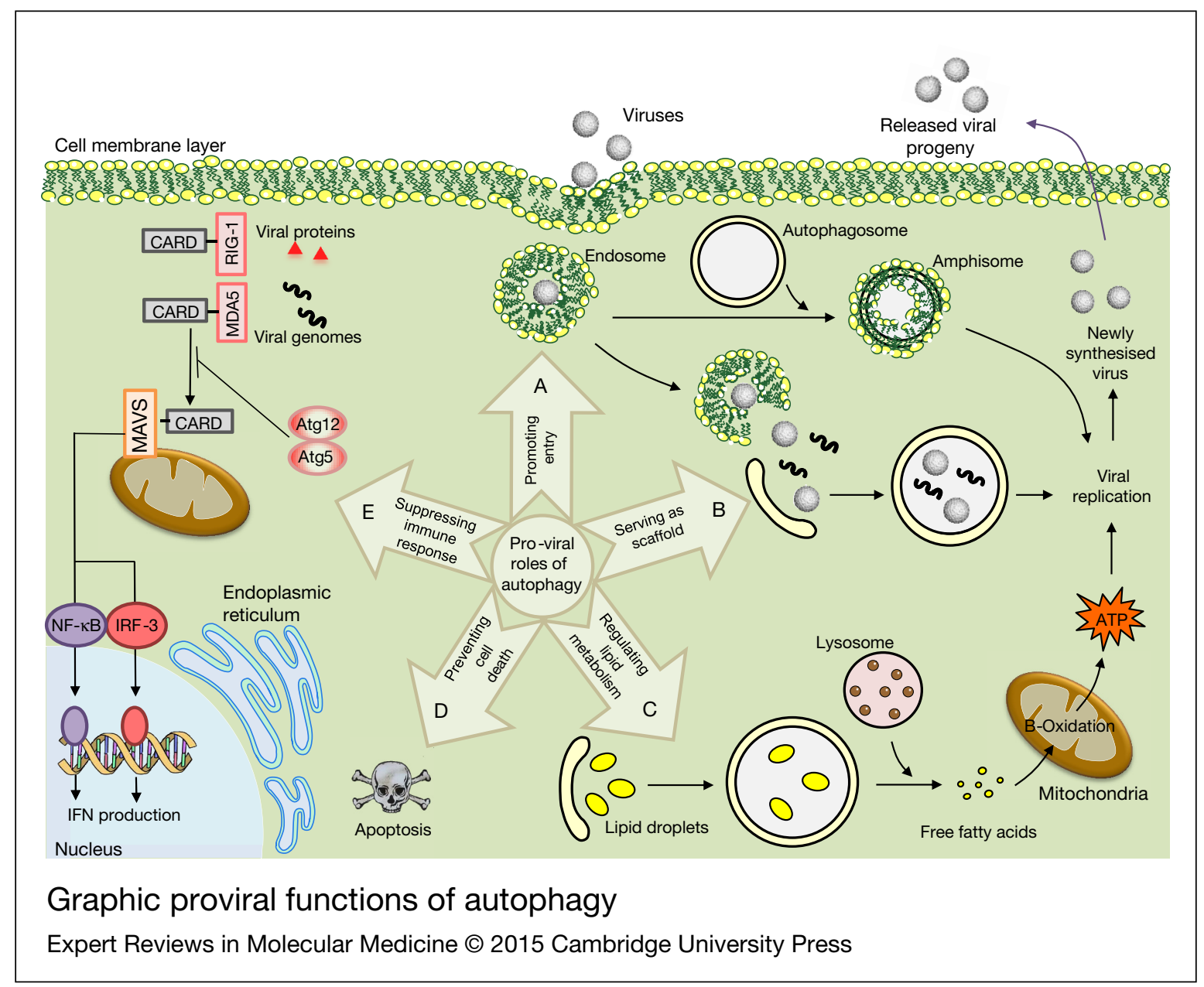

FIGURE 6.

Graphic proviral functions of autophagy. There are five possible mechanisms for modulating viral replication by autophagy. Amphisome formation is thought to be beneficial for viral cellular entry and replication. Induction of autophagosome formation is also important for some virus' replication. Furthermore, viruses initiate autophagy to benefit from lipid droplets as an energy source during viral replication. Free fatty acids are liberated from lipid droplets during autophagy to produce ATP. Viruses also stimulate autophagy to subvert immune responses by selectively degrading key regulatory molecules. Another mechanism is that viruses promote their replication by prolonging cell survival and suppressing cell death. The mechanistic details related to proviral functions of autophagy are discussed in the text.

to viral entry, regulation of lipid metabolism, suppressing innate immune responses and preventing cell death (Ref. 196). A group of arboviruses including $D E N V$, and JEV may need to invoke autophagy components such as the autophagosome, amphisome and autolysosome to: (i) serve as a scaffold for viral replication; and (ii) escape from the immune system (Refs 187, 197, 198, 199). The amphisomes play major roles in $D E N V$ entry and localisation of viral translation/replication constituents (Ref. 199). DENV2 needs pre-lysosomal fusion vacuoles (amphisomes) while $D E N V$-3 interacts with both amphisomes and autophagolysosomes as the sites for their viral translation/replication complexes (composed of viral RNA and proteins) (Ref. 199). Poliovirus and CHIKV also stimulate autophagosome formation as a site for aggregation of viral translation/replication complexes (Refs 188, 189, 200). After DENV and JEV induce autophagy, the presence of viral replication/translation complexes in both the autophagosome and the endosome suggests an auxiliary role for autophagosome-endosome fusion in viral entry (Refs 187, 201). Autophagy can regulate lipid metabolism (lipophagy) through modulating the degradation of triglycerides that have accumulated in cytosolic lipid droplets (Ref. 202). Lipid droplet usage as an energy source is another autophagy-mediated pro-viral mechanism that is used for $D E N V$ replication (Ref. 203). Thus, lipid droplets are sequestered in autophagosomes and delivered to lysosomes for degradation to generate FFAs from triglycerides (Ref. 203). The released FFAs are imported to mitochondria and they undergo $\beta$-oxidation to produce ATP for viral replication (Ref. 203).

\section{The innate antiviral immune response}

The innate antiviral response is initiated by binding of pattern recognition receptors (PRRs), retinoic acidinducible gene (RIG) and Melanoma differentiationassociated protein 5 (MDA5) to intracellular viral pathogen associated molecular patterns (PAMPs) 
(Ref. 204). The interaction of PRR-PAMP with mitochondrial antiviral-signaling protein (MAVS) through Caspase activation and recruitment domain (CARD)-CARD homotypic reaction leads to signalling cascades that ultimately activate nuclear factor$\kappa \mathrm{B}(\mathrm{NF}-\mathrm{\kappa B})$ and interferon regulatory factors (IRF-3) (Refs 205, 206). Inhibiting interferon (IFN) production followed directly from interaction of Atg5-Atg12 with the CARD of RIG, and MDA5 can promote vesicular stomatitis virus (VSV) replication (Ref. 207). Although the exact mechanism of autophagosome accumulation in $J E V$ replication is still unclear, several studies have demonstrated the importance of fusion between autophagosomes and lysosomes and also autophagy in reducing MAVS-IRF3 activation to facilitate virus replication (Ref. 208). Additionally, it has been suggested that autophagy promotes cell survival by delivering damaged mitochondria to lysosomes during $J E V$ infection (Ref. 208).

Optimal Flavivirus (e.g. DENV2) replication/translation is associated with the nonstructural viral protein NS4A in up-regulating PI3-K-dependent autophagy, and preventing cell death (Ref. 209). Recently, NS4A has been characterised as a main component of the membrane-bound $D E N V 2$ replication complexes (Ref. 210). With attention to the cross-talk between autophagy and apoptosis, it is becoming apparent that autophagy postpones apoptosis and promotes $C H I K V$ propagation by inducing the IRE1 $\alpha-X B P-1$ pathway in conjunction with ROS-mediated mTOR inhibition (Ref. 211). A schematic representation of autophagy and arbovirus replication is summarised in Figure 6.

The role of apoptosis in arbovirus replication To date, several investigations have been carried out on the importance of apoptosis in different virus infections, pathogenesis and replication, but many issues are still unclear and under debate (Refs 212, 213, 214). As summarised in Figure 7, a number of arboviruses such as Sindbis virus, $W N V$ and $J E V$ seem to use apoptosis as a virulence factor to promote their own pathogenesis $(215,216,217)$. Each of these viruses has specific targets and biochemical-induced mechanisms during virus-induced programmed cell death. The observations suggest that Sindbis virusinduced apoptosis plays an important role in Sindbis virus pathogenesis and mortality (Ref. 215). After entry of Sindbis virus into the host cell and subsequent formation of Sindbis virus double-stranded RNA intermediates, dsRNA-dependent protein kinase (PKR) recognises these particles (Refs 218, 219, 220). PKR blocks cellular translation through eIF2a phosphorylation, which later can inhibit Mcl-1 (anti-apoptotic Bcl2 family protein) biosynthesis (Ref. 221). PKR also controls c-Jun N-terminal kinases (JNK) through IRS1 phosphorylation and later activates 14-3-3 (Ref. 222). Thus, 14-3-3 affects the accessibility of substrates (e.g., Bad) to kinases and serves to localise kinases to their substrates, thereby leading to release of Bad and disruption of the complex between antiapoptotic Bcl2 family proteins, Bcl-xl and Bak. Both $\mathrm{Bad}$ and Bik can displace Bak from Mcl-1, which results in Bak oligomerization and cytochrome $\mathrm{c}$ release, and subsequent induction of apoptosis (Ref. 222). CHIKV triggers the apoptosis machinery and uses apoptotic blebs to evade immune responses and facilitate its dissemination by infecting neighboring cells (Ref. 223). CHIKV infection can induce apoptotic cell death via at least two apoptotic pathways: the intrinsic pathway, which has been reported to be involved in virus replication and results in activation of caspase-9, and the extracellular pathway, which is dependent on the induction of cell surface or soluble death effector ligands that activate caspase-8. Thus, both pathways activate caspase- 3 and finally induce cell death, and this facilitates virus release and spread (Ref. 211). The replication of Crimean-Congo haemorrhagic fever virus (CCHFV), an arbovirus from the family Bunyaviridae, is associated with the death receptor pathway of apoptosis. Up-regulation of proapoptotic proteins (i.e. BAX and HRK) and novel components of the ER stress-induced apoptotic pathways (i.e. PUMA and Noxa) have also been shown in a $C C H F V$-infected hepatocyte cell line, which suggests a link between $C C H F V$ replication, ER stress and apoptotic pathways. Notably, differential high levels of transcription factors, such as CHOP, which are activated through ER stress, are present in hepatocytes following CCHFV replication (Ref. 224). In this study, it was shown that the over-expression of IL-8, an apoptosis inhibitor, during $C C H F V$ infection was independent from apoptotic pathways. However, in other studies, a positive correlation was detected between IL-8 induction and $D E N V$ infection (Refs 224, 225, 226). In contrast to Sindbis virus, $C H I K V$ and $C C H F V$ replication in infected cells have been proposed to be necessary for apoptosis induction, as demonstrated by the use of UV-inactivated viral particles (Refs 227, 228, 229). The replication of Flaviviruses (e.g. WNV, JEV and $D E N V$ ) can be limited by virus-induced programmed cell death at the early stage of virus infection. These viruses might block or delay apoptosis via activating several cell survival pathways, such as PI3K/ Akt signalling, to improve their replication rate (Refs 227, 230). Blocking PI3K (using LY294002 and wortmannin) showed that the induction of apoptosis might be a result of p38 MAPK activation and did not affect $J E V$ and $D E N V$ viral particle production (Ref. 227). In 2001, del Carmen Parquet et al. demonstrated that WNV-induced cytopathic effect was caused during induction of apoptosis and that viral replication is an essential event for virus-induced cell death (Ref. 231). WNV capsid protein has an anti-apoptotic role, ensuring that it can block or delay apoptosis by suppression of the phosphatidylinositol (PI) 3-kinasedependent process at the early stage of infection (Ref. 230). In addition, Akt is a downstream target of PI3-kinase and can directly phosphorylate the pro- 


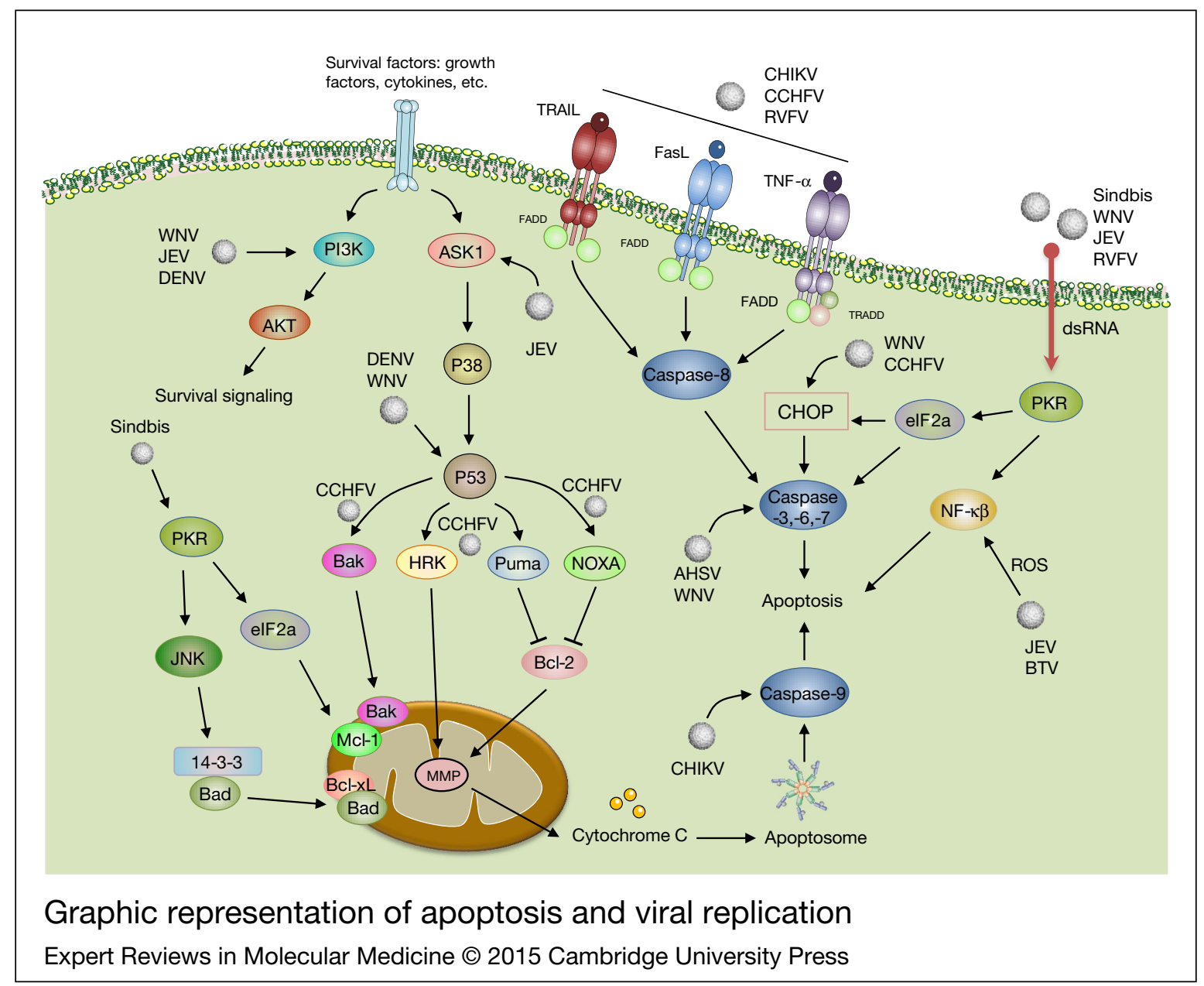

FIGURE 7.

Graphic representation of apoptosis and viral replication. Viral infection, in general, can induce both intrinsic and extrinsic apoptotic pathways. Viruses like CHIKV, CCHFV and RVFV initiate extrinsic signals through cell death ligands (e.g. FasL, APO-2L, TRAIL, TNF), causing caspases-8 activation which then triggers caspases-3, -6 and -7). AHSV and WNV directly trigger caspase 3 ; however, CHIKV targets caspase 9. DENV and WNV affect the intrinsic pathway of apoptosis through stimulation of P53. Once P53 is activated, mitochondria-dependent apoptosis can be activated. Viral infection can also induce PKR and this kinase can affect eIF2a, resulting in activation of effector caspases and initiation of apoptosis. Viruses can also have anti-apoptotic activity. DENV, WNV and JEV trigger survival signalling through PI3K-AKT signalling pathway. PKR can be initiated by Sindbis virus which leads to inhibition of cellular translation through eIF2a phosphorylation, suppressing Mcl-1 biosynthesis. Sindbis virus can regulate 14-3-3 through activation of JNK followed by induction of PKR (for other details see text). AHSV, African horse sickness virus; CHIKV, Chikungunya virus; CCHF, Crimean-Congo haemorrhagic fever virus; DENV, Dengue virus; FasL, Fas (Apo-1/CD95) ligand; JEV, Japanese encephalitis virus; JNK, c-Jun N-terminal kinases; TNF, tumour necrosis factor receptor; TRAIL, TNF-related apoptosis-inducing ligand; PKR, (dsRNA)-activated protein kinase; RVFV, Rift valley fever virus; WNV, West Nile virus.

apoptotic protein Bad at position Ser 136 (Ref. 232). $W N V$ can initiate apoptosis through caspases-3 and -12 and p53 after several rounds of replication and it is noteworthy that initial viral dose exerts an influence on kinetics of $W N V$-induced cell death (Refs 228, 233, 234, 235). After some RNA virus infections, expression of multiple miRNAs in host cells might have either a positive or negative effect on virus replication. One such cellular miRNA, Hs_154, limits $W N V$ replication by inducing apoptosis through inhibition of two anti-apoptotic proteins like CCCTC binding factor (CTCF) and EGFR-co-amplified and overexpressed protein (ECOP) (Refs 227, 236). JEV, an RNA virus, may induce ROS-mediated ASK1-ERK/p38 MAPK activation and thus lead to initiation of apoptosis (Ref. 237). In mouse neuroblastoma cells (line N18) infected with ultraviolet-inactivated $J E V$ (UV-JEV), replication-incompetent $J E V$ virions induced cell death through a ROS-dependent and NF-kB-mediated pathway (Ref. 238). Initial suppression of UV-JEVinduced cell death, followed by co-infection with active or inactive $J E V$, showed that $J E V$ may trigger cell survival signalling to modify the cell environment for timely virus production (Ref. 238). NS1' protein, a neuroinvasiveness factor that is only produced by the $J E V$ serogroup of Flaviviruses during their replication, was introduced as a caspase substrate in virusinduced apoptosis; however, use of a caspase inhibitor had no effect on virus replication (Ref. 239). Empirical evidence showed that $J E V$ can affect Bcl2 expression to increase anti-apoptotic response rather than anti-viral effect to enhance virus persistence and reach equilibrium between replication and cell death (Ref. 240). 
Numerous in vitro studies have confirmed that $D E N V$ can induce apoptosis in a wide variety of mammalian cells including endothelial cells, hepatocytes, mast cells, monocytes, dendritic cells and neuroblastoma cells, but the mechanisms are not completely understood. Dendritic cells are believed to be the primary $D E N V$ targets that play central roles in supporting active replication during virus pathogenesis. However, a recent study reported that $D E N V$ replication in monocyte-derived dendritic cells ( $\mathrm{mdDCs}$ ) was positively correlated with pro-inflammatory cytokine secretion such as TNFa and apoptosis (Ref. 241). To achieve high replication in macrophages, hepatoma and dendritic cells, $D E N V$ may subvert apoptosis by inhibiting NF-kB in response to TNFa stimulation (Refs 242, 243). Interaction between $D E N V$ capsid protein and the hepatoma cell line (Huh7) calcium modulating cyclophilin-binding ligand (CAML) also positively affected viral replication by inhibiting apoptosis (Ref. 243). Activation of p53-dependent apoptosis by $D E N V$ may also contribute to inhibition of inflammation and reduce immune responses to efficiently disseminate viral progeny (Ref. 244). Microarray analysis following $D E N V$ infection in p53-positive and -deficient cell lines revealed that activation of the pro-apoptotic gene caspase-1 played a basic role in p53-mediated apoptotic pathway and was necessary for up-regulation of numerous immune response genes (Ref. 244). As mentioned, apoptosis serves as a critical and final step in viral infectious cycles that may favour virus propagation. The pro-apoptotic NSs and anti-apoptotic NSm proteins of the Phelebovirus genus of the family Bunyaviridae (e.g. $R V F V$ ) delayed apoptosis to efficiently replicate by regulating p53 (Refs 235, 245). The $R V F V$ protein inhibits either caspase- 8 activity or the death receptor-mediated apoptotic pathway to regulate pro-apoptotic p53 signalling (Ref. 246). NSs can facilitate viral translation through inhibition of PKR/eIF2a pathway and IFN production at early stages of infection (Ref. 247). Members of the Orthobunyavirus genus, family Bunyaviridae, delay apoptosis through anti-apoptotic effects of NSs nonstructural protein on IRF-3 activity (Ref. 248).

Apoptosis has also been extensively linked to reovirus replication. $B T V$ induces apoptosis in three mammalian cell lines but not in insect cell lines that were tested. $B T V$-mediated apoptosis involved activation of $\mathrm{NF}-\mathrm{kB}$ and required virus uncoating and exposure to both outer capsid proteins VP2 and VP5 (Ref. 249). Apoptosis was mediated by both intrinsic and caspase-dependent extrinsic pathways (Ref. 250). African horse sickness virus (AHSV), another orbivirus, also induced apoptosis in mammalian BHK-21 cells but not in insect $\mathrm{KC}$ cells, through activation of caspase-3 (Ref. 251).

When apoptotic programmed cell death acts as a barrier against viral replication, previous research has revealed that some arboviruses can delay or block apoptosis to elevate their replication and dissemination. Moreover, viral replication of some arboviruses occurs following the presence of viral-induced apoptosis. However, the exact mechanisms whereby viruses modulate apoptosis in different mammalian cells need to be more extensively studied.

\section{Arboviruses and UPR}

The scientific literature related to the role of UPR in arbovirus pathogenesis is limited. Here, we review some of the arboviruses and the UPR pathways they elicit to aid replication. $W N V$ is a neurotropic arbovirus that emerged as a pathogen of serious concern in the North American population. People infected with $W N V$ are affected by severe neurological diseases such as meningitis, encephalitis and poliomyelitis (Ref. 233). WNV activates multiple UPR pathways leading to transcriptional and translational activation of several UPR target genes (Ref. 233). Of the three UPR pathways, the XBP1 pathway was shown to be non-essential for $W N V$ replication and it was replaced by other pathways. ATF6 was degraded by the proteasome and PERK transiently phosphorylated eIF2a and induced the pro-apoptotic protein CHOP (Ref. 233). $W N V$-infected cells showed signs of apoptotic cell death including induction of growth arrest, activation of caspase- 3 and activation of poly (ADPribose) polymerase (PARP). WNV titer levels were also significantly increased when grown in a $\mathrm{CHOP}^{-/-}$deficient mouse embryo fibroblast (MEF) cell line but not in wild type MEF cells (Ref. 233). This evidence showed that $W N V$ activates the UPR, and a host mechanism to counteract $W N V$ infection involved activation of CHOP-dependent cell death (Ref. 233). In another study, the $W N V$ Kunjin strain activated UPR signalling upon infection in mammalian cells (Ref. 252). UPR ATF6/IRE1 pathways were activated by this strain. However, there was no significant phosphorylation of eIF2 $\alpha$ indicating that the UPR PERK pathway was not activated (Ref. 252). The Kunjin strain nonstructural proteins, NS4A and NA4B, were potent inducers of UPR. Moreover, sequential removal of NS4A hydrophobic domains decreased UPR activation but increased interferon gamma-mediated signalling (Ref. 252). These results show that $W N V$ Kunjin strain activates UPR signalling and hydrophobic residues of WNV nonstructural proteins regulate the UPR signalling cascade. The role of ATF6 signalling in $W N V$ replication is poorly understood. Results from the same group showed that ATF6 signalling is required for $W N V$ replication by promoting cell survival and inhibition of the innate immune response (Ref. 253). ATF6-deficient cells showed a decrease in protein and virion production when infected with $W N V$ Kunjin strain. These cells also demonstrated increased eIF2a phosphorylation and CHOP transcription, but these events were absent in infected control cells (Ref. 253). In contrast, IRE I-deficient cells do not show any discernible differences when compared with IRE I-positive cells upon infection 
(Ref. 253). These results also demonstrate that, in the absence of ATF6, other UPR signalling cascades such as PERK and IRE1 pathways cannot activate or enhance virus production, indicating that ATF6 is required for viral replication. However, it has also been shown that both ATF6 and IRE I are required for signal transducer and activator of transcription (STAT) I phosphorylation, showing that ATF6 is required for inhibition of innate immune response (Ref. 253). The arboviruses $C H I K V$ and Sindbis also cause frequent epidemics of febrile illness and long-term arthralgic sequelae that affect the lives of millions of people each year (Ref. 254). These viruses replicate in infected patients and also in mammalian cells indicating that they have certain control over the UPR of the host system. Analysis of these viral infections in mammalian cells shows that CHIKV specifically activates the ATF-6 and IRE-1 branches of the UPR pathway and suppresses the PERK pathway (Ref. 254). CHIKV nonstructural protein 4 (nsp4) expression in mammalian cells suppresses eIF2 $\alpha$ phosphorylation that regulates the PERK pathway (Ref. 254). These results provide insight on the replication of CHIKV in mammalian cells by regulating the host UPR mechanism. However, experimental findings with Sindbis virus show that it induced uncontrolled UPR, which is reflected by failure to induce synthesis of ER chaperones, followed by increased phosphorylation of eIF2 $\alpha$ and activation of CHOP leading to premature cell death (Ref. 254). In another study, it was reported that the UPR XBP1 pathway was activated when neuoroblastoma N18 cells were infected with the arboviruses JEV and DENV (Ref. 255). This was evidenced by splicing of XBP1 mRNA and activation of downstream genes ERDJ4, $E D E M 1$ and $p 58$. Reduction of XBP1 by small interfering RNA had no effect on cellular susceptibility to the two viruses but enhanced cellular apoptosis (Ref. 255). Overall, these results suggest that both encephalitis and $D E N V$ trigger the XBPI signalling pathway and take advantage of this cellular response to alleviate virus induced cytotoxicity (Ref. 255). According to another group, DENV infection of A547 ovarian cancer cells elicited the UPR signalling response (Ref. 256). This was demonstrated by phosphorylation of eIF2a. It was also shown that different serotypes of $D E N V$, such as ATF6 and IRE1, activate other UPR pathways. These results show that different $D E N V$ serotypes have the capacity to modulate different UPR pathways. They also demonstrated that de-phosphorylation of eIF $2 \alpha$ by a drug called solubrinal reduced virus infection. This unique report showed that the same virus could activate all three UPR pathways (Refs 256, 257).

Initiation of UPR signalling is critical for cell survival and also for viral replication. All the above results show that arboviruses induce UPR signalling upon infection in mammalian cells. However, the UPR pathways that are activated upon infection with various arboviruses are not the same. Even different strains of the same virus activate different UPR pathways. These results suggest that specific virusinduced UPR pathway usage depends on the type of viral strain used. In vitro studies using ectopicallyexpressed arbovirus nonstructural proteins alone in mammalian cells showed that the proteins themselves can elicit the UPR response. Mutations of certain hydrophobic residues in nonstructural proteins reduced the UPR signalling response. These results indicate that composition of viral nonstructural proteins can determine the type of UPR pathway to be elicited and the extent of UPR response. Viral nonstructural proteins often undergo mutation; thus, more studies are needed to understand the role of arbovirus nonstructural proteins in inducing UPR. The role these viruses may play in UPR in the invertebrate insect cells is even less defined. Thus, induction of UPR signalling by viruses is one important facet, and equally important is how these viruses respond to anti-viral therapy. Do these viruses use the UPR pathways to decrease the effectiveness of anti-viral therapies? This is also one of the main questions to be answered. Thus, in conclusion, a significant amount of research is needed to investigate the pathogenesis of arboviruses and their relationship with UPR signalling. These studies can provide us with better antiviral therapeutics to control arbovirus replication by addressing various mechanisms of virus propagation.

\section{Conclusion}

Arbovirus infections lead to serious health issues in many parts of the world. To date, there is no treatment for most arbovirus infections and vaccines have been recently developed for only a few of these arboviruses. Therefore, finding a way to increase the efficiency of current therapeutic approaches to arbovirus infections will improve health conditions in many areas of the world. As has been discussed in this review, arbovirus infection can stimulate apoptosis, autophagy, or UPR in infected cells or organs. Activation of these pathways usually interferes with arbovirus replication and infection processes. Therefore, modulating these pathways may be a part of future strategies to combat arbovirus infections.

Apoptosis, autophagy and UPR have been widely investigated in many diseases including cancer, cardiovascular diseases and pulmonary diseases. Many inhibitors and inducers of these pathways have been developed to improve treatment protocols in these diseases. Since apoptosis, autophagy and UPR are tightly interconnected with each other and usually affect each other, it is critical to find out which pathway is the dominant one in the arbovirus infection process and how it regulates viral infection and replication in the infected cells. It is very important to identify the extent of apoptosis, autophagy, and UPR alterations in virus infected cells. After identifying these changes it would be very important to address how induction/inhibition of these pathways would modulate virus replication, and production of active viral particle in infected cells. As an 
example, we can modulate UPR using inducers (thapsigargin) or inhibitors (PERK GSK inhibitor, IRE1 inhibitor) and find out how these treatments effect arbovirus replication. These findings would provide better opportunities to use the modulation of these pathways for better designing therapeutic strategies and controlling viral infection. If this question can be clearly answered, induction or inhibition of these pathways may represent a novel enhanced treatment or prevention strategy against arbovirus infections.

\section{Acknowledgements}

S. G. was supported by University of Manitoba start up fund and the Manitoba Medical Service Foundation. J. A. was supported by University of Manitoba Start up fund. K. C. was supported by grant MT-11630 from the Canadian Institutes of Health Research. All authors acknowledge Dr Jodi Smith for final proof reading and editing.

\section{References}

1. Gubler D.J. (2002) The global emergence/resurgence of arboviral diseases as public health problems. Archives of Medical Research 33, 330-342

2. Pfeffer M. and Dobler G. (2010) Emergence of zoonotic arboviruses by animal trade and migration. Parasites \& Vectors $\mathbf{3}, 35$

3. Calisher C. and Karabatsos N. (1988) Arbovirus serogroups: definition and geographic distribution. The Arboviruses: Epidemiology and Ecology 1, 19-57

4. Heinz F.X. et al. (2000) Family Flaviviridae, Academic Press, San Diego, California

5. Weaver S. et al. (2000) Family Togaviridae, Academic Press, San Diego, CA, USA

6. Rehle T. (1989) Classification, distribution and importance of arboviruses. Tropical Medicine and Parasitology 40, 391-395

7. Knipe D. and Howley P. (2013) Fields Virology (6 edn), Wolters Kluwer Health/Lippincott Williams and Wilkins, Philadelphia, PA

8. Gubler D.J. (1997). Dengue and dengue hemorrhagic fever: its history and resurgence as a global public health problem. In Dengue and Dengue Hemorrhagic (Gubler, D.J. and Kuno, G., eds), pp. 1-22, CAB International, London

9. Weaver S.C. (2013) Urbanization and geographic expansion of zoonotic arboviral diseases: mechanisms and potential strategies for prevention. Trends In Microbiology 21, 360-363

10. Weaver S. (2005) Host range, amplification and arboviral disease emergence. In Infectious Diseases from Nature: Mechanisms of Viral Emergence and Persistence (Peters, C.J. and Calisher, C.H., eds), pp. 33-44, Springer, Vienna, Austria

11. Cavrini F. et al. (2009) Chikungunya: an emerging and spreading arthropod-borne viral disease. Journal of Infection in Developing Countries 3, 744-752

12. Lo Presti A. et al. (2014) Chikungunya virus, epidemiology, clinics and phylogenesis: a review. Asian Pacific Journal of Tropical Medicine 7, 925-932

13. Suhrbier A., Jaffar-Bandjee M.C. and Gasque P. (2012) Arthritogenic alphaviruses-an overview. Nature Reviews Rheumatology 8, 420-429

14. Jacups S.P., Whelan P.I. and Currie B.J. (2008) Ross River virus and Barmah forest virus infections: a review of history, ecology, and predictive models, with implications for tropical northern Australia. Vector Borne Zoonotic Diseases 8, 283-297

15. Tappe D. et al. (2014) O'nyong-nyong virus infection imported to Europe from Kenya by a traveler. Emerging Infectious Diseases 20, 1766-1767

16. Armstrong P.M. and Andreadis T.G. (2010) Eastern equine encephalitis virus in mosquitoes and their role as bridge vectors. Emerging Infectious Diseases 16, 1869-1874

17. Sherman M.B. and Weaver S.C. (2010) Structure of the recombinant alphavirus Western equine encephalitis virus revealed by cryoelectron microscopy. Journal of Virology 84, 9775-9782
18. Pisano M.B. et al. (2013) Venezuelan equine encephalitis viruses (VEEV) in Argentina: serological evidence of human infection. PLoS Negleted Tropical Disease 7, e2551

19. Gould E.A. and Solomon T. (2008) Pathogenic flaviviruses. Lancet 371, 500-509

20. Guzman M.G. et al. (2010) Dengue: a continuing global threat. Nature Reviews Microbiology 8(12 Suppl), S7-S16

21. Barnett E.D. (2007) Yellow fever: epidemiology and prevention. Clinical Infectious Disease 44, 850-856

22. Agampodi S.B. and Wickramage K. (2013) Is there a risk of yellow fever virus transmission in South Asian countries with hyperendemic dengue? Biomedical Research International 2013, 905043

23. Erlanger T.E. et al. (2009) Past, present, and future of Japanese encephalitis. Emerging Infectious Diseases 15, 1-7

24. Selvey L.A. et al. (2014) The changing epidemiology of Murray Valley encephalitis in Australia: the 2011 outbreak and a review of the literature. PLoS Neglected Tropical Disease 8, e2656

25. McCarthy M. (2001) St. Louis encephalitis and West Nile virus encephalitis. Current Treatment Options in Neurology 3, $433-438$

26. Petersen L.R., Brault A.C. and Nasci R.S. (2013) West Nile virus: review of the literature. JAMA 310, 308-315

27. Kiran S.K. et al. (2015) Kyasanur forest disease outbreak and vaccination strategy, Shimoga District, India, 2013-2014. Emerging Infectious Diseases 21, 146-149

28. Ruzek D. et al. (2010) Omsk haemorrhagic fever. Lancet 376, 2104-2113

29. Gresikova M. and Kaluzova M. (1997) Biology of tick-borne encephalitis virus. Acta Virologica 41, 115-124

30. Depaquit J. et al. (2010) Arthropod-borne viruses transmitted by Phlebotomine sandflies in Europe: a review. Euro Surveillance 15, 19507

31. Pepin M. et al. (2010) Rift valley fever virus (Bunyaviridae: Phlebovirus): an update on pathogenesis, molecular epidemiology, vectors, diagnostics and prevention. Veterinary Research 41, 61

32. Erwin P.C. et al. (2002) La Crosse encephalitis in Eastern Tennessee: clinical, environmental, and entomological characteristics from a blinded cohort study. American Journal of Epidemiology 155, 1060-1065

33. Appannanavar S.B. and Mishra B. (2011) An update on crimean congo hemorrhagic fever. Journal of Global Infectious Disease 3, 285-292

34. Mouraao M.P. et al. (2009) Oropouche fever outbreak, Manaus, Brazil, 2007-2008. Emerging Infectious Diseases 15, 2063-2064

35. Murray P, Rosenthal K, and Pfaller M. (2005) Medical Microbiology (4th edn), Elsevier Mosby, Philadelphia, PA

36. Shope R. (1991) Global climate change and infectious diseases. Environmental Health Perspectives 96, 171

37. Hall-Mendelin S. et al. (2010) Exploiting mosquito sugar feeding to detect mosquito-borne pathogens. Proceedings of the National Academy of Sciences 107, 11255-11259

38. Diaz Y. et al. (2015) Chikungunya virus infection: first detection of imported and autochthonous cases in panama. American Journal of Tropical Medicine and Hygiene 92, 482-485

39. Scholte F.E. et al. (2015) Stress granule components G3BP1 and G3BP2 play a proviral role early in chikungunya virus replication. Journal of Virology 89, 4457-4469

40. Gubler D. and Roehrig J. (1998) Arboviruses (Togaviridae and Flaviviridae). Topley and Wilson's Microbiology and Microbial Infections 1, 579-600

41. Guzman M.G. and Harris E. (2015) Dengue. Lancet 385, 453-465

42. WHO (2015) Dengue and severe dengue, Fact sheet $n^{\circ} 117$, Updated February 2015. Available at: http://www.who.int/ mediacentre/factsheets/fs117/en

43. WHO (2014) Yellow fever, Fact sheet $N^{\circ} 100$, Updated March 2014. Available at: http://www.who.int/mediacentre/factsheets/fs $100 /$ en/

44. Centers For Disease Control and Prevention (CDC) (On Line Source: http://www.cdc.gov/yellowfever/), (2011). Yellow Fever.

45. Ciota A.T. and Kramer L.D. (2013) Vector-virus interactions and transmission dynamics of West Nile virus. Viruses 5, 3021-3047

46. Centers For Disease Control and Prevention (CDC) (On Line Source: http:http://www.cdc.gov/westnile/statsmaps/preliminarymapsdata/index.html) (2015) West Nile Virus 
47. Weaver S.C. and Reisen W.K. (2010) Present and future arboviral threats. Antiviral Research 85, 328-345

48. WHO (2015) Chikungunya. In Media Centre, Fact sheet N³27, Updated May 2015. Available at: http://www.who. int/mediacentre/factsheets/fs327/en/

49 WHO (2014) Japanese encephalitis. In Media centre, Fact sheet No 386, March 2014. Available at: http://www.who.int/mediacentre/factsheets/fs386/en/

50. WHO (2010) Rift Valley fever. In Media Centre, Fact sheet N²07, Revised May 2010. Available at: http://www.who. int/mediacentre/factsheets/fs207/en

51. European Centre for Disease Prevention and Control (ECDPC) (2010) Limit for geographic distribution of genus Hyalomma ticks (On line source: http://ecdc.europa.eu/en/ healthtopics/vectors/ticks/Pages/hyalomma-marginatum-.aspx)

52. Go Y.Y., Balasuriya U.B. and Lee C.K. (2014) Zoonotic encephalitides caused by arboviruses: transmission and epidemiology of alphaviruses and flaviviruses. Clinical and Experimental Vaccine Research 3, 58-77

53. Pierson T.C. and Diamond M.S. (2013) flaviviruses. In Fields Virology (6 edn), (Knipe D.M. and Howley P.M. eds), pp. 747-794, Wolters Kluwer Health/Lippincott Williams and Wilkins, Philadelphia, PA

54. Anders K.L. et al. (2015) Households as foci for dengue transmission in highly urban Vietnam. PLoS Neglected Tropical Disease 9, e0003528

55. Mousson L. et al. (2012) The native Wolbachia symbionts limit transmission of dengue virus in Aedes albopictus. PLoS Neglected Tropical Disease 6, e1989

56. Mustafa M.S. et al. (2015) Discovery of fifth serotype of dengue virus (DENV-5): a new public health dilemma in dengue control. Medical Journal Armed Forces India 71, 67-70

57. Monath T.P. (1989) The Arboviruses: Epidemiology and Ecology, Volume V. CRC Press, Inc., United States

58. Nash D.T. (2001) Diabetes mellitus and cardiovascular disease. Diabetes Educator 27, 28-32, 34

59. Weaver S.C. and Barrett A.D. (2004) Transmission cycles, host range, evolution and emergence of arboviral disease. Nature Reviews Microbiology 2, 789-801

60. Elizondo-Quiroga D. and Elizondo-Quiroga A. (2013) West Nile virus and its theories, a big puzzle in Mexico and Latin America. Journal of Global Infectious Diseases 5, 168-175

61. Wimberly M.C. et al. (2013) Spatio-temporal epidemiology of human West Nile virus disease in South Dakota. International Journal of Environmental Research and Public Health 10, 5584-5602

62. Drebot M.A. et al. (2003) West Nile virus surveillance and diagnostics: a Canadian perspective. Canadian Journal of Infectious Diseases \& Medical 14, 105-114

63. Abubakr M., Mandal S.C. and Banerjee S. (2013) Natural compounds against flaviviral infections. Natural Product Communications 8, 1487-1492

64. Murray K.O. et al. (2013) West Nile virus, Texas, USA, 2012 Emerging Infectious Diseases 19, 1836-1838

65. Rosen L. (1986) The natural history of Japanese encephalitis virus. Annual Reviews in Microbiology 40, 395-414

66. Tsai T. (1997) Factors in the changing epidemiology of Japanese encephalitis and West Nile fever. Factors in the Emergence of Arboviral Diseases 179-189

67. Yun S.I. and Lee Y.M. (2014) Japanese encephalitis: the virus and vaccines. Human Vaccines \& Immunotherapeutics 10, 263-279

68. Le Flohic G. et al. (2013) Review of climate, landscape, and viral genetics as drivers of the Japanese encephalitis virus ecology. PLoS Neglected Tropical Disease 7, e2208

69. Rojanasuphot S. and Tsai T. (1995) Regional Workshop on Control Strategies for Japanese Encephalitis. Presented at the Regional Workshop on Control Strategies for Japanese Encephalitis

70. Kabilan L. et al. (2004) Japanese encephalitis in India: an overview. Indian Journal of Pediatrics 71, 609-615

71. Tiwari S. et al. (2012) Japanese encephalitis: a review of the Indian perspective. Brazilian Journal of Infectious Diseases 16, 564-573

72. Hanna J.N. et al. (1996) An outbreak of Japanese encephalitis in the Torres Strait, Australia, 1995. Medical Journal of Australia 165, 256-261

73. Verma R. (2012) Japanese encephalitis vaccine: need of the hour in endemic states of India. Human Vaccines \& Immunotherapeutics 8, 491-493
74. Pandey B. et al. (2003) Serodiagnosis of Japanese encephalitis among Nepalese patients by the particle agglutination assay. Epidemiology \& Infection 131, 881-885

75. Rainey S.M. et al. (2014) Understanding the Wolbachiamediated inhibition of arboviruses in mosquitoes: progress and challenges. Journal of General Virology 95(Pt 3), 517-530

76. Gerdes G. (2004) Rift valley fever. Revue Scientifique et Technique-Office International des Epizooties 23, 613-624

77. Meegan J. and Bailey C. (1988) Rift Valley Fever, CRC Press, United States

78. Laughlin L.W. et al. (1979) Epidemic Rift Valley fever in Egypt: observations of the spectrum of human illness. Transactions of the Royal Society of Tropical Medicine and Hygiene 73, 630-633

79. Jupp P. et al. (2002) The 2000 epidemic of Rift Valley fever in Saudi Arabia: mosquito vector studies. Medical and Veterinary Entomology 16, 245-252

80. Shoemaker T. et al. (2002) Genetic analysis of viruses associated with emergence of Rift Valley fever in Saudi Arabia and Yemen, 2000-01. Emerging Infectious Diseases 8, 1415

81. Balkhy H.H. and Memish Z.A. (2003) Rift Valley fever: an uninvited zoonosis in the Arabian Peninsula. International Journal of Antimicrobial Agents 21, 153-157

82. Bird B.H. et al. (2008) Multiple virus lineages sharing recent common ancestry were associated with a large Rift Valley fever outbreak among livestock in Kenya during 2006-2007. Journal of Virology 82, 11152-11166

83. Mohamed M. et al. (2010) Epidemiologic and clinical aspects of a Rift Valley fever outbreak in humans in Tanzania, 2007. American Journal of Tropical Medicine and Hygiene 83, 22

84. House J.A., Turell M.J. and Mebus C.A. (1992) Rift Valley fever: present status and risk to the Western Hemisphere. Annals of the New York Academy of Sciences 653, 233-242

85. Mandell R. and Flick R. (2011) Rift Valley fever virus: a real bioterror threat. Journal of Bioterrorism \& Biodefense 2, 2

86. Chevalier V. et al. (2010) Rift Valley fever--a threat for Europe? Euro Surveillance: Bulletin Europeen sur les Maladies Transmissibles $=$ European Communicable Disease Bulletin 15, 19506-19506

87. Hartley D.M. et al. (2011) Potential effects of Rift Valley fever in the United States. Emerging Infectious Diseases 17, e1

88. Walton T., Grayson M. and Monath T. (1988) The arboviruses: epidemiology and ecology. The Arboviruses: Epidemiology and Ecology 4

89. Weaver S.C. (1998) Recurrent emergence of Venezuelan equine encephalomyelitis. Emerging Infections 1, 27-42

90. Griffin D.E. (2013) Alphaviruses. In Fields Virology (Knipe D.M. and Howley P.M. eds), pp. 651-686, Wolters Kluwer Health/Lippincott Williams and Wilkins, Philadelphia, PA

91. Paessler S. and Weaver S.C. (2009) Vaccines for Venezuelan equine encephalitis. Vaccine 27 (Suppl 4), D80-D85

92. Baba M. et al. (1997) Two distinct pathways for targeting proteins from the cytoplasm to the vacuole/lysosome. Journal of Cell Biology 139, 1687-1695

93. Levine B. and Kroemer G. (2008) Autophagy in the pathogenesis of disease. Cell 132, 27-42

94. Mrschtik M. and Ryan K.M. (2015) Lysosomal proteins in cell death and autophagy. FEBS Journal 282, 1858-1870

95. Fernandez A.F. and Lopez-Otin C. (2015) The functional and pathologic relevance of autophagy proteases. Journal of Clinical Investigation 125, 33-41

96. Klionsky D.J. and Emr S.D. (2000) Autophagy as a regulated pathway of cellular degradation. Science 290, 1717-1721

97. Mortimore G.E., Reeta Pösö A. and Lardeux B.R. (1989) Mechanism and regulation of protein degradation in liver. Diabetes / Metabolism Reviews 5, 49-70

98. Ghavami S. et al. (2014) Autophagy and heart disease: implications for cardiac ischemia-reperfusion damage. Current Molecular Medicine 14, 616-629

99. Papadopoulos T. and Pfeifer U. (1987) Protein turnover and cellular autophagy in growing and growth-inhibited 3T3 cells. Experimental Cell Research 171, 110-121

100. Mizushima N. (2007) Autophagy: process and function. Genes \& Development 21, 2861-2873

101. Xilouri M. and Stefanis L. (2015) Chaperone mediated autophagy to the rescue: A new-fangled target for the treatment of neurodegenerative diseases. Molecular and Cellular Neuroscience 66, 29-36 
102. Napolitano G. et al. (2015) Impairment of chaperone-mediated autophagy leads to selective lysosomal degradation defects in the lysosomal storage disease cystinosis. EMBO Molecular Medicine e201404223

103. Kawamura N. et al. (2012) Delivery of endosomes to lysosomes via microautophagy in the visceral endoderm of mouse embryos. Nature Communications 3, 1071

104. Cuervo A.M. and Wong E. (2014) Chaperone-mediated autophagy: roles in disease and aging. Cell Research 24, 92-104

105. Jia G. and Sowers J.R. (2015) Autophagy: a housekeeper in cardiorenal metabolic health and disease. Biochimica et Biophysica Acta (BBA)-Molecular Basis of Disease 1852, 219-224

106. Yang Y.-p. et al. (2005) Molecular mechanism and regulation of autophagy. Acta Pharmacologica Sinica 26, 1421-1434

107. Bursch W. (2001) The autophagosomal-lysosomal compartment in programmed cell death. Cell Death and Differentiation 8, 569

108. Majeski A.E. and Fred Dice J. (2004) Mechanisms of chaperone-mediated autophagy. International Journal of Biochemistry \& Cell Biology 36, 2435-2444

109. Mijaljica D., Prescott M. and Devenish R.J. (2011) Microautophagy in mammalian cells: revisiting a 40-yearold conundrum. Autophagy 7, 673-682

110. Voigt O. and Poggeler S. (2013) Self-eating to grow and kill: autophagy in filamentous ascomycetes. Applied Microbiology and Biotechnology 97, 9277-9290

111. Lemasters J.J. (2014) Variants of mitochondrial autophagy: types 1 and 2 mitophagy and micromitophagy (Type 3). Redox Biology 2, 749-754

112. Yang Z. and Klionsky D.J. (2010) Eaten alive: a history of macroautophagy. Nature Cell Biology 12, 814-822

113. Grasso D. and Vaccaro M.I. (2014) Macroautophagy and the oncogene-induced senescence. Frontiers in Endocrinology (Lausanne) 5, 157

114. Klionsky D.J. and Schulman B.A. (2014) Dynamic regulation of macroautophagy by distinctive ubiquitin-like proteins. Nature Structural \& Molecular Biology 21, 336-345

115. Dice J.F. (2000) Lysosomal Pathways of Protein Degradation, Landes Bioscience, Austin, TX

116. Tooze S.A. (2013) Current views on the source of the autophagosome membrane. Essays in Biochemistry 55, 29-38

117. Pattingre S. et al. (2008) Regulation of macroautophagy by mTOR and Beclin 1 complexes. Biochimie 90, 313-323

118. Hurley J.H. and Schulman B.A. (2014) Atomistic autophagy: the structures of cellular self-digestion. Cell 157, 300-311

119. Levine B. and Yuan J. (2005) Autophagy in cell death: an innocent convict? Journal of Clinical Investigation 115, 2679-2688

120. Shibutani S.T. and Yoshimori T. (2014) A current perspective of autophagosome biogenesis. Cell research 24, 58-68

121. Klionsky D.J. et al. (2003) A unified nomenclature for yeast autophagy-related genes. Developmental Cell 5, 539-545

122. Xie Y. et al. (2015) Posttranslational modification of autophagy-related proteins in macroautophagy. Autophagy 11, 28-45

123. Mizushima N. (2010) The role of the Atg1/ULK1 complex in autophagy regulation. Current Opinion in Cell Biology 22, $132-139$

124. Hall M. (2008) mTOR-what does it do? In Transplantation Proceedings 40, Elsevier

125. Mercer C.A., Kaliappan A. and Dennis P.B. (2009) A novel, human Atg13 binding protein, Atg101, interacts with ULK1 and is essential for macroautophagy. Autophagy 5, 649-662

126. Chiarini F. et al. (2015) Current treatment strategies for inhibiting mTOR in cancer. Trends in Pharmacological Sciences 36, $124-135$

127. Jung C.H. et al. (2010) mTOR regulation of autophagy. FEBS letters 584, 1287-1295

128. Czarny P. et al. (2015) Autophagy in DNA damage response. International Journal of Molecular Sciences 16, 2641-2662

129. Simonsen A. and Tooze S.A. (2009) Coordination of membrane events during autophagy by multiple class III PI3kinase complexes. Journal of Cell Biology 186, 773-782

130. Morel E., Dupont N. and Codogno P. (2014) Autophagy regulation: RNF2 targets AMBRA1. Cell Research 24, 1029-1030

131. Jordan T.X. and Randall G. (2012) Manipulation or capitulation: virus interactions with autophagy. Microbes and Infection 14, 126-139
132. Kabeya Y. et al. (2000) LC3, a mammalian homologue of yeast Apg8p, is localized in autophagosome membranes after processing. EMBO Journal 19, 5720-5728

133. Slobodkin M.R. and Elazar Z. (2013) The Atg8 family: multifunctional ubiquitin-like key regulators of autophagy. Essays in Biochemistry 55, 51-64

134. Matsunaga K. et al. (2009) Two Beclin 1-binding proteins, Atg14L and Rubicon, reciprocally regulate autophagy at different stages. Nature Cell Biology 11, 385-396

135. Zhong Y. et al. (2009) Distinct regulation of autophagic activity by $\operatorname{Atg} 14 \mathrm{~L}$ and Rubicon associated with Beclin 1-phosphatidylinositol-3-kinase complex. Nature Cell Biology 11, 468-476

136. Mizushima N. et al. (2008) Autophagy fights disease through cellular self-digestion. Nature 451, 1069-1075

137. Call J.A., Eckhardt S.G. and Camidge D.R. (2008) Targeted manipulation of apoptosis in cancer treatment. Lancet Oncology 9, 1002-1011

138. Yeganeh B. et al. (2013) Asthma and influenza virus infection: focusing on cell death and stress pathways in influenza virus replication. Iranian Journal of Allergy, Asthma and Immunology 12, 1-17

139. Rashedi I. et al. (2007) Autoimmunity and apoptosis--therapeutic implications. Current Medicinal Chemistry 14, 3139-3151

140. Fulda S. and Debatin K. (2006) Extrinsic versus intrinsic apoptosis pathways in anticancer chemotherapy. Oncogene 25, 4798-4811

141. Ghavami S. et al. (2009) Apoptosis and cancer: mutations within caspase genes. Journal of Medical Genetics 46, 497-510

142. Ghavami S. et al. (2005) Apoptosis in liver diseases-detection and therapeutic applications. Medical Science Monitor 11, RA337-RRA45

143. Hassan M. et al. (2014) Apoptosis and molecular targeting therapy in cancer. BioMed Research International, 150845

144. Ghavami S. et al. (2014) Autophagy and apoptosis dysfunction in neurodegenerative disorders. Progress in Neurobiology 112, 24-49

145. Shalini S. et al. (2015) Old, new and emerging functions of caspases. Cell Death \& Differentiation 22, 526-539

146. Fuchs Y. and Steller H. (2011) Programmed cell death in animal development and disease. Cell 147, 742-758

147. Kubli D.A. and Gustafsson A.B. (2012) Mitochondria and mitophagy: the yin and yang of cell death control. Circulation Research 111, 1208-1221

148. Er E. et al. (2006) Mitochondria as the target of the pro-apoptotic protein Bax. Biochimica et Biophysica Acta (BBA)Bioenergetics 1757, 1301-1311

149. Crow M.T. et al. (2004) The mitochondrial death pathway and cardiac myocyte apoptosis. Circulation Research 95, 957-970

150. Ghavami S. et al. (2010) Statin-triggered cell death in primary human lung mesenchymal cells involves p53-PUMA and release of Smac and Omi but not cytochrome c. Biochim Biophys Acta 1803, 452-467

151. Ghavami S. et al. (2008) S100A8/9 induces cell death via a novel, RAGE-independent pathway that involves selective release of Smac/DIABLO and Omi/HtrA2. Biochim Biophys Acta 1783, 297-311

152. Petros A.M., Olejniczak E.T. and Fesik S.W. (2004) Structural biology of the Bcl-2 family of proteins. Biochimica et Biophysica Acta (BBA)-Molecular Cell Research 1644, 83-94

153. Kim E. et al. (2014) Nuclear and cytoplasmic p53 suppress cell invasion by inhibiting respiratory Complex-I activity via Bcl-2 family proteins. Oncotarget 5, 8452-8465

154. Ghavami S. et al. (2009) Role of BNIP3 in TNF-induced cell death-TNF upregulates BNIP3 expression. Biochimica et Biophysica Acta (BBA)-Molecular Cell Research 1793, 546560

155. Saelens X. et al. (2004) Toxic proteins released from mitochondria in cell death. Oncogene 23, 2861-2874

156. Wang K. (2014) Molecular mechanisms of liver injury: apoptosis or necrosis. Experimental and Toxicologic Pathology 66, 351-356

157. Ghavami S. et al. (2004) Mechanism of apoptosis induced by S100A8/A9 in colon cancer cell lines: the role of ROS and the effect of metal ions. Journal of Leukocyte Biology 76, 169-175

158. Wu C.C. and Bratton S.B. (2013) Regulation of the intrinsic apoptosis pathway by reactive oxygen species. Antioxidants \& Redox Signaling 19, 546-558 
159. Moll U.M. and Zaika A. (2001) Nuclear and mitochondrial apoptotic pathways of p53. FEBS letters 493, 65-69

160. Ghavami S. et al. (2011) Mevalonate cascade regulation of airway mesenchymal cell autophagy and apoptosis: a dual role for p53. PloS ONE 6, e16523

161. Reed S.M. and Quelle D.E. (2014) p53 acetylation: regulation and consequences. Cancers (Basel) 7, 30-69

162. Michalak E. et al. (2008) In several cell types tumour suppressor p53 induces apoptosis largely via Puma but Noxa can contribute. Cell Death \& Differentiation 15, 1019-1029

163. Zhang L.N., Li J.Y. and Xu W. (2013) A review of the role of Puma, Noxa and Bim in the tumorigenesis, therapy and drug resistance of chronic lymphocytic leukemia. Cancer Gene Therapy 20, 1-7

164. Peng Y. et al. (2015) Baicalein induces apoptosis of human cervical cancer HeLa cells in vitro. Molecular Medicine Reports 11, 2129-2134

165. Tilly J.L. (2001) Commuting the death sentence: how oocytes strive to survive. Nature Reviews Molecular Cell Biology 2, 838-848

166. Li P. et al. (1997) Cytochrome c and dATP-dependent formation of Apaf-1/ caspase-9 complex initiates an apoptotic protease cascade. Cell 91, 479-489

167. Pour-Jafari H., Ghavami S. and Maddika S. (2005) Mitochondrial physiology and toxicity (Mitotoxicity); importance for the immune system, programmed cell death and cancer. Current Medicinal Chemistry-Anti-Inflammatory \& Anti-Allergy Agents 4, 439-448

168. Saveljeva S. et al. (2015) Endoplasmic reticulum stress induces ligand-independent TNFR1-mediated necroptosis in L929 cells. Cell Death \& Disease 6, e1587

169. Sovolyova N. et al. (2014) Stressed to death - mechanisms of ER stress-induced cell death. Biological Chemistry 395, 1-13

170. Hetz C., Chevet E. and Harding H.P. (2013) Targeting the unfolded protein response in disease. Nature Reviews Drug Discovery 12, 703-719

171. Logue S.E. et al. (2013) New directions in ER stress-induced cell death. Apoptosis 18, 537-546

172. Guan B.J. et al. (2014) Translational control during endoplasmic reticulum stress beyond phosphorylation of the translation initiation factor eIF2alpha. Journal of Biological Chemistry 289, 12593-12611

173. Kozutsumi Y. et al. (1988) The presence of malfolded proteins in the endoplasmic reticulum signals the induction of glucoseregulated proteins. Nature 332, 462-464

174. Hetz C. (2012) The unfolded protein response: controlling cell fate decisions under ER stress and beyond. Nature Reviews Molecular Cell Biology 13, 89-102

175. Lin J.H. et al. (2007) IRE1 signaling affects cell fate during the unfolded protein response. Science 318, 944-949

176. Coelho D.S., Gaspar C.J. and Domingos P.M. (2014) Ire1 mediated mRNA splicing in a C-terminus deletion mutant of Drosophila Xbp1. PloS ONE 9, e105588

177. $\mathrm{Yu}$ B. et al. (2014) Single prolonged stress induces ATF6 alpha-dependent endoplasmic reticulum stress and the apoptotic process in medial frontal cortex neurons. BMC Neuroscience 15, 115

178. Yoshida H. et al. (2001) XBP1 mRNA is induced by ATF6 and spliced by IRE1 in response to ER stress to produce a highly active transcription factor. Cell 107, 881-891

179. Guo F.J. et al. (2014) ATF6 upregulates XBP1S and inhibits ER stress-mediated apoptosis in osteoarthritis cartilage. Cellular Signalling 26, 332-342

180. Doyle K.M. et al. (2011) Unfolded proteins and endoplasmic reticulum stress in neurodegenerative disorders. Journal of Cellular and Molecular Medicine 15, 2025-2039

181. Donnelly N. et al. (2013) The eIF2alpha kinases: their structures and functions. Cellular and Molecular Life Sciences 70, 3493-3511

182. Novoa I. et al. (2001) Feedback inhibition of the unfolded protein response by GADD34-mediated dephosphorylation of eIF2alpha. Journal of Cell Biology 153, 1011-1022

183. Cullinan S.B. et al. (2003) Nrf2 is a direct PERK substrate and effector of PERK-dependent cell survival. Molecular and Cellular Biology 23, 7198-7209

184. Shelly S. et al. (2009) Autophagy is an essential component of $<\mathrm{i}>$ Drosophila immunity against vesicular stomatitis virus. Immunity 30, 588-598
185. Orvedahl A. et al. (2010) Autophagy protects against Sindbis virus infection of the central nervous system. Cell Host \& Microbe 7, 115-127

186. Lee Y.-R. et al. (2008) Autophagic machinery activated by dengue virus enhances virus replication. Virology 374, $240-248$

187. Li J.-K. et al. (2012) Autophagy is involved in the early step of Japanese encephalitis virus infection. Microbes and Infection 14, 159-168

188. Krejbich-Trotot P. et al. (2011) Chikungunya triggers an autophagic process which promotes viral replication. Virology Journal 8, 432

189. Meng S. et al. (2012) Avian reovirus triggers autophagy in primary chicken fibroblast cells and Vero cells to promote virus production. Archives of Virology 157, 661-668

190. Shai B. et al. (2013) Epizootic hemorrhagic disease virus induces and benefits from cell stress, autophagy, and apoptosis. Journal of Virology 87, 13397-13408

191. Arnoldi F. et al. (2014) Rotavirus increases levels of lipidated LC3 supporting accumulation of infectious progeny virus without inducing autophagosome formation. PloS ONE 9, e95197

192. Heaton N.S. and Randall G. (2011) Dengue virus and autophagy. Viruses 3, 1332-1341

193. Panyasrivanit M. et al. (2011) Induced autophagy reduces virus output in dengue infected monocytic cells. Virology 418, 74-84

194. Vandergaast R. and Fredericksen B.L. (2012) West Nile virus (WNV) replication is independent of autophagy in mammalian cells. PloS ONE 7, e45800

195. Lee Y.-R. et al. (2013) Dengue virus infection induces autophagy: an in vivo study. Journal of Biomedical Science 20, 65

196. Shi J. and Luo H. (2012) Interplay between the cellular autophagy machinery and positive-stranded RNA viruses. Acta Biochimica et Biophysica Sinica 44, 375-384

197. Chi P.I. et al. (2013) The p17 nonstructural protein of avian reovirus triggers autophagy enhancing virus replication via activation of phosphatase and tensin deleted on chromosome 10 (PTEN) and AMP-activated protein kinase (AMPK), as well as dsRNA-dependent protein kinase (PKR)/eIF $2 a$ signaling pathways. Journal of Biological Chemistry 288, 3571-3584

198. den Boon J.A. and Ahlquist P. (2010) Organelle-like membrane compartmentalization of positive-strand RNA virus replication factories. Annual Review of Microbiology 64, 241-256

199. Panyasrivanit M. et al. (2009) Co-localization of constituents of the dengue virus translation and replication machinery with amphisomes. Journal of General Virology 90, 448-456

200. Jackson W.T. et al. (2005) Subversion of cellular autophagosomal machinery by RNA viruses. PLoS Biology 3, e156

201. Panyasrivanit M. et al. (2009) Linking dengue virus entry and translation/replication through amphisomes. Autophagy 5, 434-435

202. Singh R. and Cuervo A.M. (2012) Lipophagy: connecting autophagy and lipid metabolism. International Journal of Cell Biology, 282041

203. Heaton N.S. and Randall G. (2010) Dengue virus-induced autophagy regulates lipid metabolism. Cell Host \& Microbe 8, 422-432

204. Jensen S. and Thomsen A.R. (2012) Sensing of RNA viruses: a review of innate immune receptors involved in recognizing RNA virus invasion. Journal of Virology 86, 2900-2910

205. Loo Y.-M. et al. (2008) Distinct RIG-I and MDA5 signaling by RNA viruses in innate immunity. Journal of Virology 82, 335-345

206. Hou F. et al. (2011) MAVS forms functional prion-like aggregates to activate and propagate antiviral innate immune response. Cell 146, 448-461

207. Jounai N. et al. (2007) The Atg5-Atg12 conjugate associates with innate antiviral immune responses. Proceedings of the National Academy of Sciences 104, 14050-14055

208. Jin R. et al. (2013) Japanese encephalitis virus activates autophagy as a viral immune evasion strategy. PloS ONE 8, e52909

209. McLean J.E. et al. (2011) Flavivirus NS4A-induced autophagy protects cells against death and enhances virus replication. Journal of Biological Chemistry 286, 22147-22159 
210. Miller S. et al. (2007) The non-structural protein 4A of dengue virus is an integral membrane protein inducing membrane alterations in a 2 K-regulated manner. Journal of Biological Chemistry 282, 8873-8882

211. Joubert P.-E. et al. (2012) Chikungunya virus-induced autophagy delays caspase-dependent cell death. Journal of Experimental Medicine 209, 1029-1047

212. Collins M. (1995) Potential roles of apoptosis in viral pathogenesis. American Journal of Respiratory and Critical Care Medicine 152, S20

213. Clarke P. et al. (2014) Death receptor-mediated apoptotic signaling is activated in the brain following infection with West Nile virus in the absence of a peripheral immune response. Journal of Virology 88, 1080-1089

214. Turpin E. et al. (2005) Influenza virus infection increases p53 activity: role of p53 in cell death and viral replication. Journal of Virology 79, 8802-8811

215. Lewis J. et al. (1996) Alphavirus-induced apoptosis in mouse brains correlates with neurovirulence. Journal of Virology $\mathbf{7 0}$, 1828-1835

216. Samuel M.A., Morrey J.D. and Diamond M.S. (2007) Caspase 3-dependent cell death of neurons contributes to the pathogenesis of West Nile virus encephalitis. Journal of Virology 81, 2614-2623

217. Sun J., Yu Y. and Deubel V. (2012) Japanese encephalitis virus NS1' protein depends on pseudoknot secondary structure and is cleaved by caspase during virus infection and cell apoptosis. Microbes and Infection 14, 930-940

218. Stollar V., Shenk T.E. and Stollar B.D. (1972) Doublestranded RNA in hamster, chick, and mosquito cells infected with Sindbis virus. Virology 47, 122-132

219. Stollar B.D. and Stollar V. (1970) Immunofluorescent demonstration of double-stranded RNA in the cytoplasm of Sindbis virus-infected cells. Virology 42, 276-280

220. Domingo-Gil E. et al. (2011) Diversity in viral anti-PKR mechanisms: a remarkable case of evolutionary convergence. PloS ONE 6, e16711

221. Akgul C. (2009) Mcl-1 is a potential therapeutic target in multiple types of cancer. Cellular and Molecular Life Sciences 66, 1326-1336

222. Venticinque L. and Meruelo D. (2010) Sindbis viral vector induced apoptosis requires translational inhibition and signaling through Mcl-1 and Bak. Molecular Cancer 9, 37

223. Krejbich-Trotot P. et al. (2011) Chikungunya virus mobilizes the apoptotic machinery to invade host cell defenses. FASEB Journal 25, 314-325

224. Rodrigues R. et al. (2012) Crimean-Congo hemorrhagic fever virus-infected hepatocytes induce ER-stress and apoptosis crosstalk. PloS ONE 7, e29712

225. Medin C.L. and Rothman A.L. (2006) Cell type-specific mechanisms of interleukin- 8 induction by dengue virus and differential response to drug treatment. Journal of Infectious Diseases 193, 1070-1077

226. Li A. et al. (2003) IL-8 directly enhanced endothelial cell survival, proliferation, and matrix metalloproteinases production and regulated angiogenesis. Journal of Immunology $\mathbf{1 7 0}$, 3369-3376

227. Lee C.-J., Liao C.-L. and Lin Y.-L. (2005) Flavivirus activates phosphatidylinositol 3-kinase signaling to block caspasedependent apoptotic cell death at the early stage of virus infection. Journal of Virology 79, 8388-8399

228. van Marle G. et al. (2007) West Nile virus-induced neuroinflammation: glial infection and capsid protein-mediated neurovirulence. Journal of Virology 81, 10933-10949

229. Jan J.-T. and Griffin D.E. (1999) Induction of apoptosis by Sindbis virus occurs at cell entry and does not require virus replication. Journal of Virology 73, 10296-10302

230. Urbanowski M.D. and Hobman T.C. (2013) The West Nile virus capsid protein blocks apoptosis through a phosphatidylinositol 3-Kinase-dependent mechanism. Journal of Virology 87, 872-881

231. del Carmen Parquet M. et al. (2001) West Nile virus-induced bax-dependent apoptosis. FEBS Letters 500, 17-24

232. Fujikura D. et al. (2012) CLIPR-59 regulates TNF- $\alpha$-induced apoptosis by controlling ubiquitination of RIP1. Cell Death \& Disease 3, e264

233. Medigeshi G.R. et al. (2007) West Nile virus infection activates the unfolded protein response, leading to CHOP induction and apoptosis. Journal of Virology 81, 1084910860

234. Chu J. and Ng M. (2003) The mechanism of cell death during West Nile virus infection is dependent on initial infectious dose. Journal of General Virology 84, 3305-3314

235. Yang M.R. et al. (2008) West Nile virus capsid protein induces p53-mediated apoptosis via the sequestration of HDM2 to the nucleolus. Cellular Microbiology 10, 165-176

236. Smith J.L. et al. (2012) Induction of the cellular microRNA, Hs_154, by West Nile virus contributes to virus-mediated apoptosis through repression of antiapoptotic factors. Journal of Virology 86, 5278-5287

237. Yang T.-C. et al. (2010) Japanese encephalitis virus down-regulates thioredoxin and induces ROS-mediated ASK1-ERK/ p38 MAPK activation in human promonocyte cells. Microbes and Infection 12, 643-651

238. Lin R.-J., Liao C.-L. and Lin Y.-L. (2004) Replication-incompetent virions of Japanese encephalitis virus trigger neuronal cell death by oxidative stress in a culture system. Journal of General Virology 85, 521-533

239. Melian E.B. et al. (2010) NS1' of flaviviruses in the Japanese encephalitis virus serogroup is a product of ribosomal frameshifting and plays a role in viral neuroinvasiveness. Journal of Virology 84, 1641-1647

240. Liao C.-L. et al. (1998) Antiapoptotic but not antiviral function of humanbcl-2 assists establishment of Japanese encephalitis virus persistence in cultured cells. Journal of Virology 72, 9844-9854

241. Silveira G.F. et al. (2011) Dengue virus type 3 isolated from a fatal case with visceral complications induces enhanced proinflammatory responses and apoptosis of human dendritic cells. Journal of Virology 85, 5374-5383

242. Palmer D.R. et al. (2005) Differential effects of dengue virus on infected and bystander dendritic cells. Journal of Virology 79, 2432-2439

243. Li J. et al. (2012) Dengue virus utilizes calcium modulating cyclophilin-binding ligand to subvert apoptosis. Biochemical and Biophysical Research Communications 418, 622-627

244. Nasirudeen A. and Liu D.X. (2009) Gene expression profiling by microarray analysis reveals an important role for caspase-1 in dengue virus-induced p53-mediated apoptosis. Journal of Medical Virology 81, 1069-1081

245. Austin D. et al. (2012) p53 Activation following Rift Valley fever virus infection contributes to cell death and viral production. PloS ONE 7, e36327

246. Won S. et al. (2007) NSm protein of Rift Valley fever virus suppresses virus-induced apoptosis. Journal of Virology 81, 13335-13345

247. Ikegami T. et al. (2009) Rift Valley fever virus NSs protein promotes post-transcriptional downregulation of protein kinase PKR and inhibits eIF2 $\alpha$ phosphorylation. PLoS Pathogens 5, e1000287

248. Kohl A. et al. (2003) Bunyamwera virus nonstructural protein NSs counteracts interferon regulatory factor 3-mediated induction of early cell death. Journal of Virology 77, 79998008

249. Mortola E., Noad R. and Roy P. (2004) Bluetongue virus outer capsid proteins are sufficient to trigger apoptosis in mammalian cells. Journal of Virology 78, 2875-2883

250. Nagaleekar V.K. et al. (2007) Bluetongue virus induces apoptosis in cultured mammalian cells by both caspase-dependent extrinsic and intrinsic apoptotic pathways. Archives of Virology 152, 1751-1756

251. Stassen L., Huismans H. and Theron J. (2012) African horse sickness virus induces apoptosis in cultured mammalian cells. Virus Research 163, 385-389

252. Ambrose R.L. and Mackenzie J.M. (2011) West Nile virus differentially modulates the unfolded protein response to facilitate replication and immune evasion. Journal of Virology $\mathbf{8 5}$, 2723-2732

253. Ambrose R.L. and Mackenzie J.M. (2013) ATF6 signaling is required for efficient West Nile virus replication by promoting cell survival and inhibition of innate immune responses. Journal of Virology 87, 2206-2214

254. Rathore A.P., Ng M.L. and Vasudevan S.G. (2013) Differential unfolded protein response during Chikungunya and Sindbis virus infection: CHIKV nsP4 suppresses eIF2alpha phosphorylation. Virology Journal 10, 36 
255. Yu C.Y. et al. (2006) Flavivirus infection activates the XBP1 pathway of the unfolded protein response to cope with endoplasmic reticulum stress. Journal of Virology 80, 11868-11880

256. Umareddy I. et al. (2007) Dengue virus serotype infection specifies the activation of the unfolded protein response. Virology Journal 4, 91

257 Fraser J.E. et al. (2014). A nuclear transport inhibitor that modulates the unfolded protein response and provides in vivo protection against lethal Dengue virus infection. Journal of Infectious Diseases 210, 1780-1791, doi: 10.1093/infdis/jiu319
*Corresponding author:

Saeid Ghavami

Department of Human Anatomy and Cell Science,

College of Medicine,

Faculty of Health Sciences,

University of Manitoba,

Winnipeg, Canada.

Tel: +1 204272 3061;

E-mail: Saeid.Ghavami@umanitoba.ca, Saeid.Ghavami@gmail.com 